\title{
PUESTA EN VALOR DEL PATRIMONIO INMUEBLE CHILENO A TRAVES DE LA SOSTENIBILIDAD Y LA IMPLEMENTACIÓN DE MODELOS DE GESTIÓN ${ }^{(*)}$ \\ VALUE ASSESSMENT OF THE CHILEAN BUILT HERITAGE THROUGH SUSTAINABILITY AND IMPLEMENTATION OF MANAGEMENT MODELS
}

\author{
ROMINA RAZETO URIOSTE ${ }^{[\star]}$ \\ Fecha de recepción: 02 de noviembre de 2015 \\ Fecha de aprobación: 25 de noviembre de 2015
}

\section{RESUMEN}

Este artículo analiza los programas adoptados por el Gobierno chileno para la puesta en valor del patrimonio construido. La puesta en valor se entiende como un reconocimiento de los valores presentes en los monumentos en cuestión. Dicho reconocimiento es efectivo en tanto conlleva las medidas necesarias para la conservación, recuperación y evaluación de la edificación. En ese sentido, el concepto de sostenibilidad es indispensable para entender la gestión del patrimonio a largo plazo. Tomando esto en consideración, en el artículo se describen los criterios utilizados para el desarrollo del programa de puesta en valor del patrimonio chileno y, en particular, de los modelos de gestión implementados. Son estos los instrumentos que hacen posible la sostenibilidad y la conservación del patrimonio construido a largo plazo.

\section{PALABRAS CLAVE}

Puesta en valor, sostenibilidad, modelo de gestión

\section{ABSTRACT}

This article analyzes the programs adopted by the Chilean Government for the value assessment of its built heritage. Value assessment is a recognition of the present values in these monuments. This recognition is effective only when it carries the necessary measures for the conservation, recovery and evaluation of the edification. In that sense, the concept of sustainability concept is indispensable for understanding heritage management in the long-term. Considering this, in the article the criteria that has been used for the development of the value assessment program of Chilean heritage, in particular regarding the implemented management models, are described, for these are the instruments that make possible the sustainability and conservation of the built heritage long term in the long term.

\section{KEYWORDS}

Value assessment, sustainability, management model

(*) El siguiente artículo fue desarrollado a partir de una investigación sobre los criterios de intervención, titulada Análisis Comparativo entre Restauración Iglesia de Socoroma, Comuna de Putre y Restauración Templo Virgen Santa Isabel de Caype, Distrito Lambrana, desarrollado en las clases de Metodología y Crítica de la Conservación en 2014-2, dictada por el Mg. Arq. José Hayakawa Casas en el marco académico de la Escuela de Posgrado de la Facultad de Arquitectura, Urbanismo y Artes de la Universidad Nacional de Ingeniería del Perú.

$\left.{ }^{(* *}\right)$ Arquitecta con 8 años de experiencia laboral. Trabajó en la Unidad Regional de la Subsecretaria de Desarrollo Regional y Administrativo de la región de Arica y Parinacota entre los 2012-2014. Actualmente se encuentra cursando la Maestría de Conservación y Gestión de Patrimonio Edificado en la Escuela de Post-Grado de la Facultad de Arquitectura, Urbanismo y Artes de la Universidad Nacional de Ingeniería del Perú. Contacto: rrazeto@gmail.com 
Desde la elaboración de los primeros instrumentos de conservación del patrimonio, $L a$ Carta de Atenas de 1931, por ejemplo, se reconoce la importancia de restaurar y preservar los edificios patrimoniales. Sin embargo, no basta con ello; es indispensable la administración, seguridad y mantenimiento de los edificios en el tiempo. Considerando el alto costo económico, ya sea privado o público, que conlleva esta tarea, las inversiones deben asegurar la puesta en valor de los bienes patrimoniales, así como su manejo integral. La conservación integral, a nivel nacional, requiere de la incorporación y el manejo territorial, financiero, legislativo y social para hacer posible la sostenibilidad del patrimonio arquitectónico (Consejo de Europa, 1975). Sin embargo, estos elementos también deben integrarse a nivel de edificio; es así como desde las teorías económicas surgen herramientas, como la administración y la gestión, que permiten la adecuada puesta en valor y manejo integral de los bienes patrimoniales en el tiempo. Por este motivo, el objetivo general de este artículo es analizar el concepto de 'puesta en valor' y, particularmente, su utilización e implementación como elemento ordenador dentro de los modelos de gestión aplicados al patrimonio cultural inmueble en Chile.

\section{Desarrollo del Programa Puesta en Valor del Patrimonio en Chile}

De acuerdo a lo que señala la Carta de Venecia (1964), "La noción de monumento histórico comprende tanto la creación arquitectónica aislada, como el ambiente urbano o paisajístico que constituya el testimonio de una civilización particular, de una evolución significativa o de un acontecimiento histórico" (p. 1). La anterior definición introduce los valores que se le asigna a los monumentos históricos, a partir de los cuales se le otorga un reconocimiento simbólico o histórico al edificio. Desde este punto de vista, la puesta en valor es en principio el reconocimiento de los valores presentes en estos monumentos y, a su vez, la capacidad de destacarlos mediante las intervenciones o proyectos a realizar en estos bienes; es decir, "La puesta en valor implica la asignación de importancia, ya sea local, nacional o internacional, desde una serie de puntos de vista: estética, científica, social, política, cultural y económica, entre otras" (Mason, 2002, p. 9)

Además, se debe considerar que la correcta puesta en valor de un bien patrimonial implica una actuación integral para su preservación, recuperación y valoración. Por ello es relevante la sostenibilidad del bien en el tiempo, entendiendo "el desarrollo sostenible, como el desarrollo con futuro que garantiza la satisfacción de las necesidades de las generaciones actuales y futuras sin comprometer los recursos naturales $y$ humanos" (ONU, 1992, pp. 1-2)

La sostenibilidad como concepto, en la conservación y restauración, se ve reflejada desde los inicios en la Carta de Venecia (1964), la cual señala que "Las obras monumentales de los pueblos, portadoras de un mensaje espiritual del pasado, representan en la vida actual el testimonio vivo de sus tradiciones seculares. La humanidad, que cada día toma conciencia de los valores humanos, las considera patrimonio común reconociéndose responsable de su salvaguardia frente a las generaciones futuras" (p. 1). Al afirmar la responsabilidad de la humanidad en la salvaguarda del patrimonio para generaciones futuras, este pasa a ser un recurso humano único que se debe utilizar de manera adecuada en el presente, sin comprometer su estado o uso, es decir, que debe ser manejado de manera sostenible.

Las diversas formas en que las intervenciones de restauración y conservación logran potenciar los valores de los bienes patrimoniales ofrecen una oportunidad para lograr la sostenibilidad a largo plazo de las inversiones realizadas para su puesta en valor. Es importante destacar que cada uno de los valores reconocidos en el patrimonio arquitectónico interesa a distintos actores sociales: los inversionistas inmobiliarios se interesan en el valor de uso, los operadores turísticos en su atractivo para los visitantes, la comunidad en su valor espiritual y de herencia, y el Gobierno en su valor educacional y cultural. Por ello estos actores son fundamentales al visionar una propuesta de puesta en valor, ya 
que serán estos actores los que posteriormente se involucrarán en la puesta en marcha y consecución de la propuesta, ya sea como sus propulsores, inversionistas o cuidadores; asimismo, finalmente serán ellos los que evaluarán el resultado de la iniciativa.

Si consideramos que los bienes patrimoniales son potenciales recursos económicos, no solo desde el área turística, sino también social, y que en la mayoría de los casos estas construcciones pertenecen al Estado, las intervenciones que presenten y propongan un nuevo uso o tipología no necesariamente deben enfocarse en el mercado turístico, sino también en el bienestar social. Las iniciativas que incorporen el beneficio a la comunidad, con programas de apoyo en áreas económicas y educacionales, permitirán que las propuestas de conservación y restauración se transformen en proyectos de puesta en valor con gran relevancia social.

Asimismo, es importante mencionar que, ya sea en iniciativas de conservación y restauración como en planes de manejo integral, es primordial la integración de profesionales y técnicos de diversas áreas de estudio, de manera que se completen eficazmente todas las aristas que permitan un diseño arquitectónico y constructivo adecuado, una gestión administrativa y financiera correcta, y la difusión y educación en torno al patrimonio arquitectónico.

Desde este punto de vista, se examina el concepto de puesta en valor y manejo integral, donde, además de la incorporación de un nuevo uso acorde con el edificio, operan distintos ámbitos de intervención estratégica como la administración y gestión, el grado de significación y la identidad de la comunidad sobre este, la aprobación del proyecto o plan de trabajo por parte de la población encargada de su resguardo, la mantención y seguridad, entre otros. Para lograr dicha intervención estratégica se recurrirá al concepto de gestión, a modo de eje transversal que permitirá accionar y direccionar las iniciativas, tal como se analizará más adelante.

A partir del concepto de puesta en valor se ha instaurado en Chile desde el año 2008 el Programa Puesta en Valor del Patrimonio (PPV), que fue financiado hasta 2014 mediante un préstamo del Banco Interamericano de Desarrollo (BID), bajo la modalidad Préstamo en Función de Resultados. Este programa actualmente sigue en ejecución, financiado por la Subsecretaria de Desarrollo Regional (SUBDERE), de acuerdo a glosa de presupuesto 2016. Desde sus inicios el principal órgano ejecutor del programa fue la SUBDERE, dependencia del Ministerio del Interior de Chile. En su guía operativa se señala que el programa financiará: a) acciones para proteger y poner en valor activos patrimoniales inmuebles, b) actividades de fortalecimiento institucional de los organismos responsables de las inversiones y de la operación sostenible de los activos, y c) actividades de difusión del programa y del valor del patrimonio (SUBDERE, 2011, p. 1)

Es interesante destacar la organización y el planeamiento del programa, que se llevó a cabo mediante convenios entre las distintas entidades gubernamentales involucradas. Entre los involucrados se pueden mencionar a la Dirección de Arquitectura, $\mathrm{Mi}-$ nisterio de Obras Públicas (DA-MOP), uno de los entes encargados del área técnica del proyecto con su departamentos de patrimonio; las unidades regionales de la SUBDERE, encomendadas a gestionar los recurso desde el nivel central a las regiones; los Gobiernos Regionales (GORES) que cuentan con un mayor conocimiento de la población beneficiaria y, a la vez, son propulsores de las iniciativas a nivel local; la Secretaria Regional del Ministerio de Desarrollo Social, quienes evalúan el ingreso de la iniciativa al Banco Integrado de Proyectos para la obtención de recursos; entre otros actores.

El programa define 'puesta en valor del patrimonio' como "Las intervenciones sobre bienes patrimoniales declarados Monumentos Nacionales o en proceso de serlo, que hacen posible que éstos generen flujos sostenidos de beneficios culturales, sociales y económicos para la comunidad" (SUBDERE, 2011, p. 2). En este caso la puesta en valor se entiende principalmente como un recurso humano capaz de generar beneficios 
desde la valoración entregada a un bien (cultural, social o económico), para lo cual se utilizan diferentes actividades, por ejemplo, la recuperación física y funcional de los inmuebles. Se trata de acciones que aseguren la sustentabilidad de la puesta en valor de los bienes patrimoniales y del sistema territorial del que son parte, que sensibilicen y hagan partícipe a la ciudadana, así como estudios o declaraciones de impacto, ambiental de, ser necesarios, de acuerdo al diseño.

La Guía Operativa del Programa Puesta en Valor del Patrimonio del Ministerio del Interior, ejecutada por SUBDERE, señala en su punto 6.3 los criterios específicos de evaluación para la etapa de Ejecución de proyecto (Obras). En el punto iii señala los siguientes requisitos para su aprobación:

Estar declarado Monumento Nacional; debe contar con la aprobación del Consejo de Monumentos Nacionales para el Proyecto de Intervención Patrimonial (Diseño); y con un modelo de gestión sustentable, existiendo un sostenedor público o privado comprometido en efectuar una gestión sostenible que ofrezca razonables garantías de que los beneficios esperados del proyecto se mantengan en el tiempo y que los gastos de operación y mantención contarán con financiamiento durante el horizonte de tiempo de vida útil del proyecto. (SUBDERE, 2011, p. 21)

Es decir, al referirse al modelo de gestión como plan o informe ya elaborado en la etapa de ejecución de obras de restauración o habilitación, se asegurará la inversión realizada a largo plazo. En otras palabras, antes de que la intervención y la inversión se realicen, ya se cuenta con un enfoque de manejo del inmueble a futuro que le permitirá ser sostenible en el tiempo.

Como requisito del BID, para el préstamo que financió la ejecución del Programa Puesta en Valor del Patrimonio entre los años 2008 y 2014, la SUBDERE contrató mediante licitación pública una consultora externa para realizar el estudio de evaluación final del programa, en el cual se analizó y evaluó lo siguiente: a) el sistema de identificación y selección de proyectos, b) las acciones de puesta en valor del patrimonio y c) los mecanismos de gestión aplicados para la sostenibilidad de los inmuebles puestos en valor por el programa. Esta evaluación permitió hacer un balance del programa; sin embargo, es importante realizar análisis posteriores a la ejecución de las obras, ya que este recurso de seguimiento ayudará a corregir los sistemas de gestión ya implementados a largo plazo y, así, mejorar aquellos que efectuarán a futuro.

Emplear la guía operativa del programa como instrumento ha permitido dar una rápida mirada al Programa Puesta en Valor del Patrimonio. Este busca no solo restaurar y habilitar el patrimonio arquitectónico deteriorado y en desuso, sino también integrar diversos ámbitos de acción que permitan la sostenibilidad del bien a largo plazo. Para ello ha utilizado el fortalecimiento de las instituciones involucradas; la elaboración de los estudios necesarios, ya sean de prefactibilidad, factibilidad, diseño u otros; la implementación de los modelos de gestión adecuados para cada caso; y, por último, la difusión y educación en torno al patrimonio. A pesar de que aún es pronto para ver los verdaderos avances e impactos de programa, todos estos elementos y herramientas son un paso importante y relevante para concretar la sostenibilidad del patrimonio arquitectónico.

\section{Aplicación del Concepto Gestión al Patrimonio Arquitectónico}

Cuando se diseña un proyecto de conservación y restauración de un monumento histórico, por lo general, se inicia con los antecedentes históricos y constructivos de la edificación. Se realiza, por un lado, un estudio detallado de su cronología, en que se destacan las condiciones en que se originó la obra y quiénes fueron sus propietarios, $y$, desde el punto de vista constructivo, se detalla sus sistemas estructurales y su calidad edificatoria, como cuáles son sus materiales originales, cuál es su situación actual, cuánto deterioro presenta y los daños que ha sufrido, cuál el uso original para el que 
fue construido el bien. Todos estos antecedentes son de suma importancia al proyectar una intervención, ya que brindan la información necesaria para destacar los valores con que cuenta un inmueble patrimonial. Sin embargo, hoy en día las metodologías y la planificación de intervenciones en el patrimonio arquitectónico deben ampliar el horizonte e integrar métodos que permitan la sostenibilidad del edificio.

Para brindarle sostenibilidad a un monumento histórico, se debe pensar desde el inicio en una adecuada gestión posintervención. Para ello cabe enfatizar en el concepto de gestión y cómo este se ha ejecutado a través de los modelos de gestión para hacer efectiva la sostenibilidad de los monumentos históricos.

La palabra gestión procede del latín gestion, que quiere decir hecho concluido, y el sufijo -onis, que significa acción y efecto; de ahí se entiende 'gestión' como llevar adelante una iniciativa o un proyecto; es decir, la acción y el efecto de gestionar o administrar (“gestión", 2013).

El concepto de gestión se utiliza en general para hablar de proyectos o de cualquier tipo de actividad que requiera procesos de planificación, administración, coordinación y control: “De modo que la gestión, organizacionalmente hablando, se refiere al desarrollo de las funciones básicas de la administración: Planear, organizar, dirigir y controlar" (Amat, 1992, p. 270). Según lo anterior, la gestión se concibe en los diversos ámbitos que permiten la ejecución de un proyecto, por lo cual está presente en todas las áreas de las iniciativas y proyectos, ya sea en los ámbitos públicos o privados.

De acuerdo a lo que señala Mauricio Sanabria (2007), "la gestión consiste en una actividad transversal a la organización que puede ser desarrollada de diversos modos y grados, en sus diferentes ámbitos y subsistemas" (p.166-167). Ello quiere decir que la gestión se entiende como un eje transversal que propone y pone en marcha las acciones pertinentes para que un proyecto sea exitoso. Si, por ejemplo, se considera el caso del estado como organización, entonces la gestión como actividad transversal involucrará actividades de actores de las diversas instituciones gubernamentales que forman parte del mismo.

Por lo señalado, se puede concluir que la gestión puede ser aplicada a todas las áreas y etapas de un proyecto, ya sea desde el inicio o en su puesta en marcha. En el caso del patrimonio arquitectónico, si se aplica la gestión una vez concluida la intervención de conservación o restauración, y una vez decidido el nuevo uso del monumento, esta permitirá la planificación y proyección de las diversas áreas para un adecuado manejo del bien. Esto implica que se ejecuten las tareas necesarias que permitan el autofinanciamiento del patrimonio arquitectónico como recurso para su mantención y funcionamiento en el tiempo, así como su protección y seguridad, su sostenibilidad y, por lo tanto, su resguardo para generaciones futuras.

\section{Aplicación de Modelos de Gestión en el Caso Chileno}

Siguiendo los lineamientos de la Guía Operativa del Programa Puesta en Valor del Patrimonio, dado que los modelos de gestión son un instrumento relevante dentro del programa, cabe comentar su uso a partir de la definición que presenta la guía operativa: "Diseño y ejecución de las acciones vinculadas a la implementación de los modelos de administración y gestión de los proyectos de puesta en valor patrimonial financiados por el programa, o de proyectos ejecutados que requieren de un impulso para asegurar su operación y mantenimientos sustentable..." (p. 8).

Como se señaló anteriormente, la gestión se refiere a las diferentes operaciones necesarias para lograr un objetivo. Por su parte, 'modelo' se refiere a un arquetipo, o punto de referencia, a imitar o reproducir ("modelo", 2013). Es decir, un modelo representa algo real, en un momento determinado; por lo tanto, al ejecutar un modelo se levan- 
Tabla 1. Estructura, Modelo de Gestión

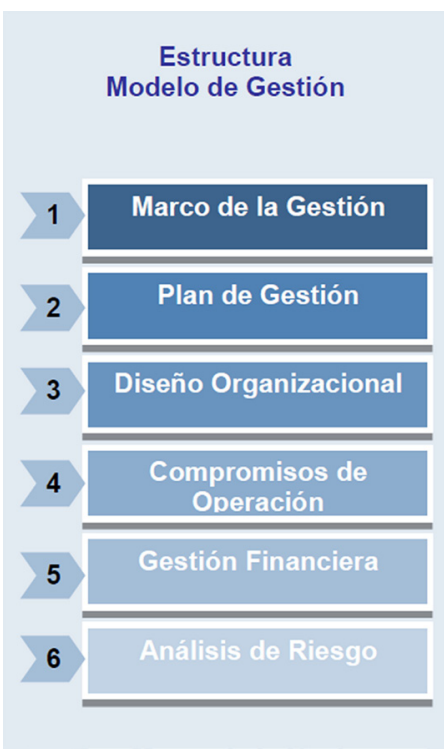

Fuente: SUBDERE, 2010, p. 11.
Tabla 2. Contenido, Marco de Gestión

\begin{tabular}{|c|c|c|c|c|c|c|}
\hline \multicolumn{7}{|c|}{ MARCO DE GESTIÓN } \\
\hline ANTECEDENTE & \multicolumn{6}{|c|}{ CONTENIDO } \\
\hline $\begin{array}{l}\text { Identificación del } \\
\text { Modelo }\end{array}$ & \multicolumn{6}{|c|}{ Nombre de la tipología propuesta } \\
\hline \multirow{3}{*}{ Identificación del Bien } & \multicolumn{2}{|l|}{ Descripción General } & \multicolumn{4}{|c|}{ Ubicación } \\
\hline & \multicolumn{2}{|l|}{ Propiedad } & \multicolumn{4}{|c|}{ (incluir plano de ubicación) } \\
\hline & \multicolumn{2}{|c|}{ Categoría de Monumento } & \multicolumn{4}{|c|}{ 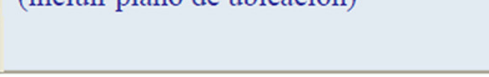 } \\
\hline $\begin{array}{l}\text { Identificación de los } \\
\text { Valores del bien }\end{array}$ & \multicolumn{2}{|l|}{$\begin{array}{l}\text { Valor Estético } \\
\text { Valor Histórico } \\
\text { Valor Cientifico } \\
\text { Valor Social }\end{array}$} & \multicolumn{4}{|c|}{$\begin{array}{l}\text { Valor de Paisaje } \\
\text { Valor Arquitectónico } \\
\text { Valor Constructivo } \\
\text { Otros Valores }\end{array}$} \\
\hline Identificación del Uso & Uso Propuesto & \multicolumn{3}{|c|}{ Uso Actual } & \multicolumn{2}{|c|}{ Uso Original } \\
\hline \multirow{3}{*}{$\begin{array}{l}\text { Identificación del } \\
\text { Administrador }\end{array}$} & $\begin{array}{l}\text { Antecedentes de la } \\
\text { Organización }\end{array}$ & \multicolumn{2}{|c|}{ Nombre } & $\begin{array}{l}\text { Dirección } \\
\text { Teléfono }\end{array}$ & Misión & Estructura \\
\hline & $\begin{array}{l}\text { Antecedentes del } \\
\text { Representante Legal }\end{array}$ & \multicolumn{2}{|c|}{ Nombre } & Cargo & \multicolumn{2}{|c|}{ Responsabilidad } \\
\hline & Recursos Disponibles & \multicolumn{2}{|c|}{ Humanos } & Físicos & \multicolumn{2}{|c|}{ Financieros } \\
\hline \multirow{2}{*}{$\begin{array}{l}\text { Identificación de } \\
\text { variables que } \\
\text { condicionan el uso }\end{array}$} & \multicolumn{2}{|c|}{ Normas-Reglamentaciones } & \multicolumn{4}{|c|}{ Derechos sobre la propiedad } \\
\hline & \multicolumn{2}{|l|}{ Capacidad de Carga } & \multicolumn{4}{|c|}{ Otras variables } \\
\hline
\end{tabular}

Fuente: SUBDERE, 2010, p. 12.

tará la información necesaria, a cierto nivel de detalle, que permitirá comprender esa realidad de manera simple y aprehensible. Un modelo se realiza con un propósito específico y con puntos de vistas individuales, pues se elabora a partir de la mirada de quienes lo construyen, por lo que muestra diversas perspectivas. Por ello, para un adecuado y similar ordenamiento de estos instrumentos, es importante tener acceso a sus lineamientos generales. Con este fin, la SUBDERE propone la Guía Metodológica para la Elaboración de Modelos de Gestión del Patrimonio Cultural Inmueble (2010).

En el caso del Programa Puesta en Valor del Patrimonio, el modelo o la realidad que se espera interpretar es la manera en que se aplica la gestión, por parte de los actores involucrados, en la organización que tiene o tendrá a su cargo un inmueble patrimonial: "Modelar la administración del patrimonio inmueble entonces puede lograrse con una explicación detallada del proceso administrativo que se lleva a cabo dentro de las organizaciones que tienen a su cargo un inmueble" (SUBDERE, 2010, p. 4).

Un adecuado modelo de gestión determinará en primer lugar el uso original y actual del inmueble; posteriormente, recomendará un uso adecuado para este, respetando las particularidades que presenta. Para ello identificará los valores que muestra el patrimonio inmueble; a los administradores del bien; y las variables que condicionan su uso, su modo de planificar y organizar su ocupación por un período determinando de tiempo, considerando que la mejor manera de conservar los inmuebles patrimoniales es su ocupación permanente y dirigida. De acuerdo a la Guía Metodológica Para la Elaboración de Modelos de Gestión del Patrimonio Cultural Inmueble (2010), la estructura de un modelo de gestión recomendado es el siguiente: a) "Marco de la Gestión", b) "Plan de Gestión", c) “Diseño Organizacional”, d) “Compromisos de Operación”, e) “Gestión Financiera" y f) "Análisis de Riesgo" (Tabla 1). 
Tabla 3. Contenido, Plan de Gestión

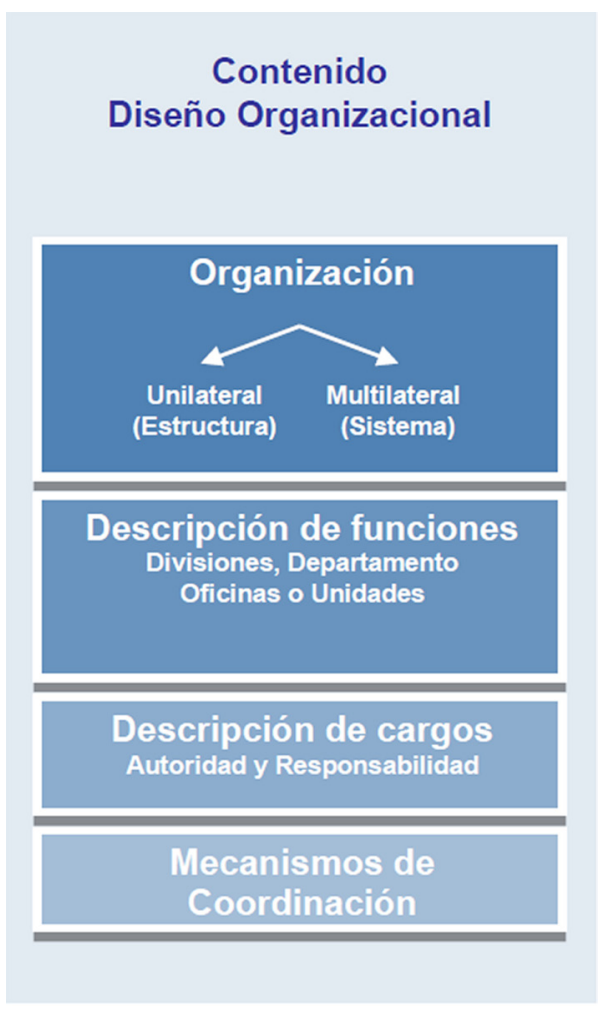

Fuente: SUBDERE, 2010, p. 14
Tabla 4. Contenido, Diseño Organizacional

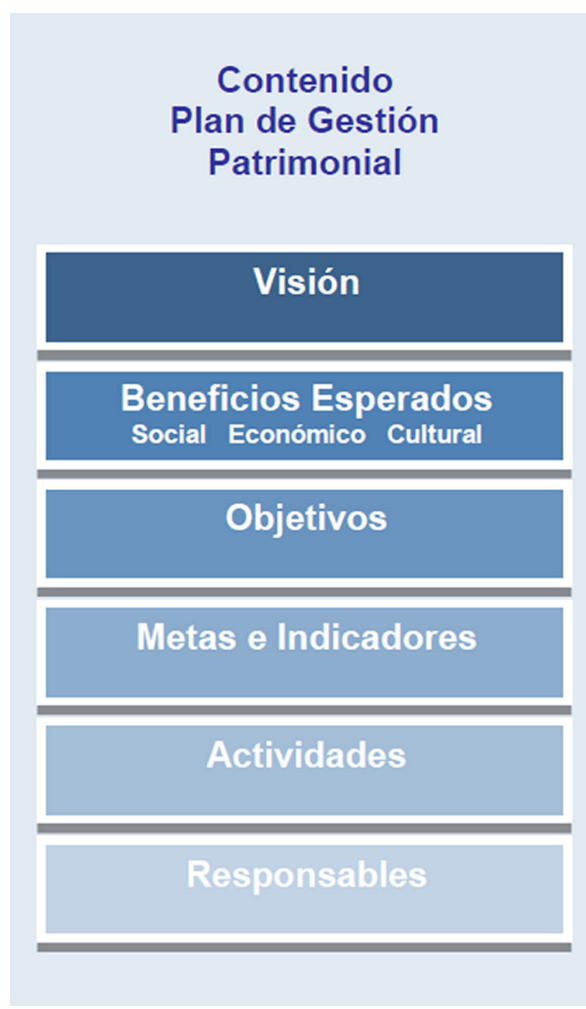

Fuente: SUBDERE, 2010, p. 14.

El primer punto, "Marco de Gestión", se entiende como una introducción, que presentará los antecedentes previos y un diagnostico que guiará las decisiones posteriores (Tabla 2).

En el punto dos, "Plan de Gestión", se definirán las acciones concretas para la puesta en marcha de la iniciativa y, además, se concretará la situación del uso o destino del inmueble patrimonial (Tabla 3).

A continuación, en "Diseño Organizacional", se presentará los actores involucrados en la administración del bien, y los cargos y funciones que se les asignará; en resumen, se desarrollará un organigrama específico para la administración del bien (Tabla 4).

En la etapa "Compromisos de Operación", se desarrollará las actividades que permitirán la sostenibilidad del bien patrimonial. Posteriormente, mediante la gestión financiera, se valorizará el costo de cumplir con los compromisos antes mencionados, para luego precisar el volumen de los ingresos que se necesitan obtener para cubrir esos costos. Es decir, el costo se calculará a partir de la suma de las tareas definidas en los compromisos de operación, costo de mantención costo de protección y costo de la administración general del inmueble (Tabla 5).

Finalmente, en "Análisis de Riesgo", se realizará un estudio sobre los diversos escenarios posibles que pudieran afecta el modelo de gestión del proyecto.

De esta estructura cabe revisar detalladamente el punto iii ("Compromisos Operacionales"), ya que en este se detallan los elementos que permiten reconocer y plantear las acciones necesarias para el correcto funcionamiento del patrimonio arquitectónico como recurso sostenible. Son cuatro los contenidos priorizados: operación, mantención, seguridad y promoción (Tabla 6). 
Tabla 5. Contenido, Compromisos de Operación

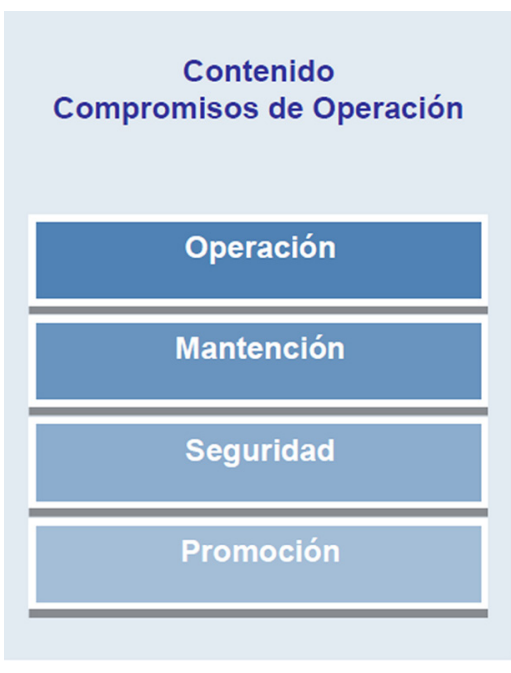

Fuente: SUBDERE, 2010, p. 17.
Tabla 6. Contenido, Gestión Financiera

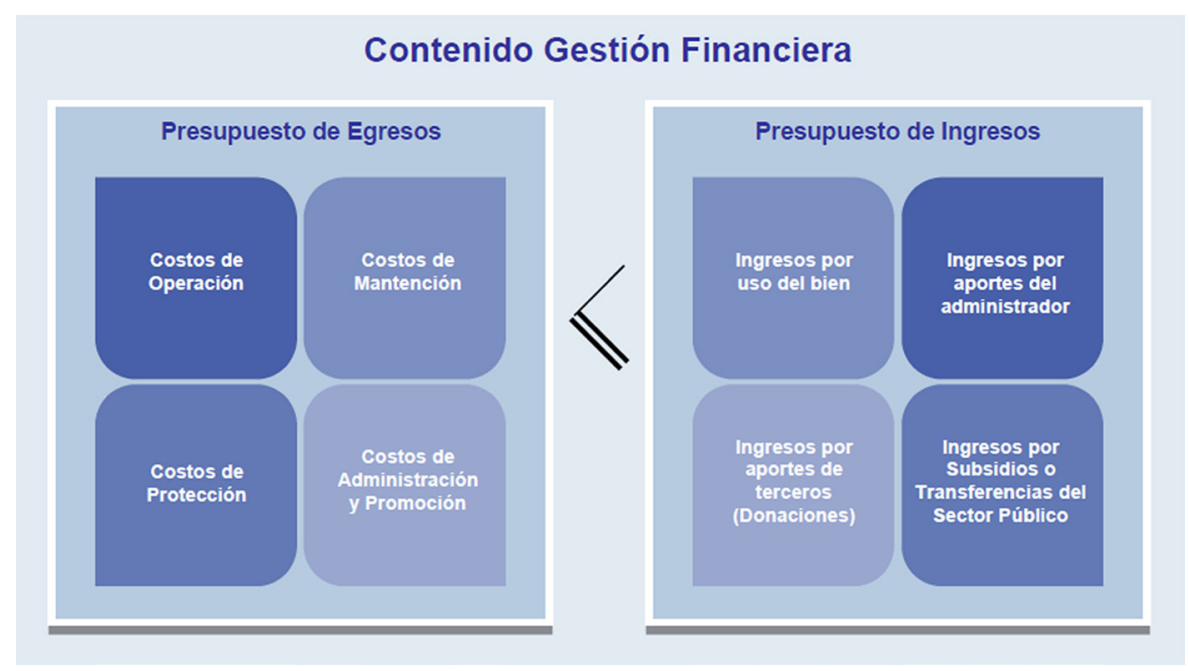

Fuente: SUBDERE, 2010, p. 15.

La operación definirá todas las tareas y requerimientos necesarios a realizar para que el bien cumpla el uso previsto, por ejemplo, una iglesia en la que se realizarán ceremonias de eucaristías, matrimonios, bautismos, festividades, etc. Asimismo, se listará al personal necesario para dichos quehaceres. La mantención implica el conjunto de tareas que ayudan al cuidado del bien con el fin de evitar su deterioro físico, como la limpieza, el lavado de pisos y fachadas, la manutención de instalaciones, etc. Se refiere a las tareas que permiten evitar el deterioro a corto plazo o de uso diario del bien. De acuerdo a la Guía Metodológica (2010), "La restauración implica intervenciones mayores que requieren de un proyecto especial que no es del caso incorporar a los modelos, sólo basta mencionar la iniciativa y presentar una breve descripción" (p. 16). La seguridad refiere las tareas vinculadas a la vigilancia y protección del bien en otras palabras, a las precauciones para evitar los actos vandálicos, los robos y los saqueos de bienes patrimoniales. Por último, la promoción se encargará de la difusión que informe y capte la atención de la comunidad, los turistas o los visitantes. Dependiendo del uso otorgado, la promoción deberá enfocarse en atraer a la población, que será el medio para generar recursos económicos para el sustento del bien. La adecuada organización y planificación de los trabajos antes mencionados permitirán sostener el bien a mediano y largo plazo.

Es importante resaltar que un plan de manejo no es lo mismo que un modelo gestión. El primero se vincula directamente a la administración del bien, mientras que el segundo busca la sostenibilidad y conservación del mismo, empleando no solo la administración, sino también la preservación de dicho bien.

A continuación se analizarán los modelos de gestión aprobados de tres edificios declarados monumentos históricos. Se trata obras con usos distintos, de manera que permiten comparar las propuestas y las herramientas utilizadas.

\section{Modelo de Gestión de la Iglesia San Francisco de Asís de Socoroma}

La restauración de iglesia de Socoroma se enmarca dentro del Plan de Restauración del Conjunto Patrimonial de Iglesias Andinas de Arica y Parinacota. El modelo de gestión propuesto para el conjunto patrimonial se basa en la valorización del uso y gestión tradicional de las iglesias andinas como lugares de culto católico, y centros de preservación de la cultura y religiosidad tradicional de los poblados. 


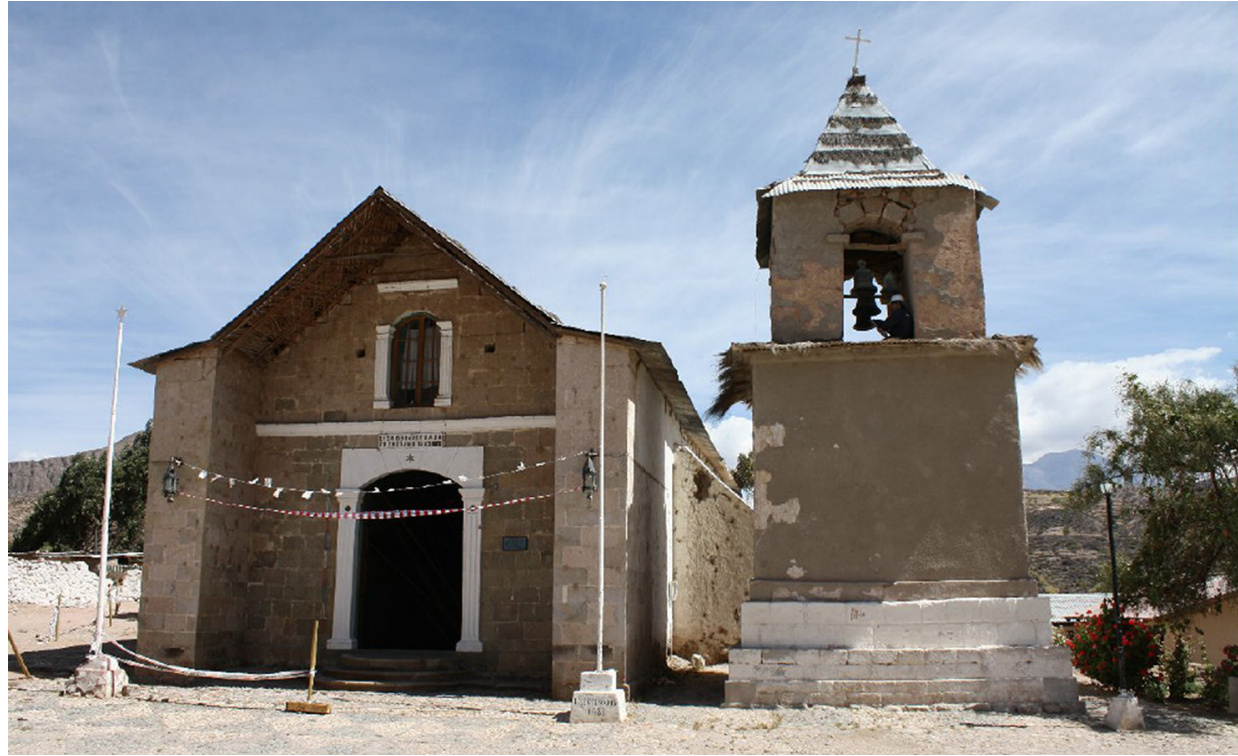

Figura 1. Fachada de la Iglesia de Socoroma antes de la intervención

Fuente: SUBDERE, 2014, p. 27

Figura 2. Plano Elevación de Fachada Fuente: SUBDERE, 2014, p. 65

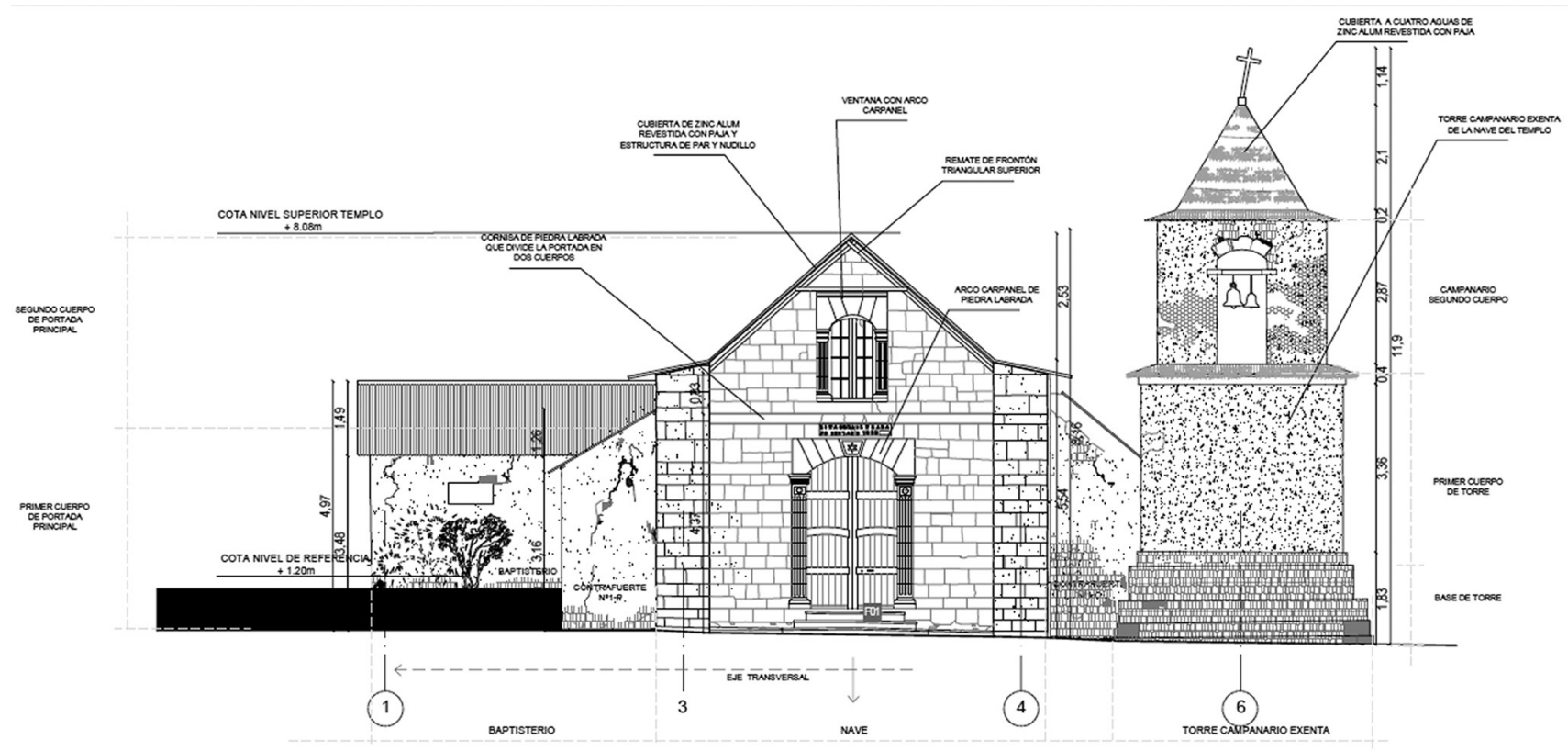

Posteriormente al levantamiento y diagnóstico de los antecedentes, el modelo de gestión analiza los valores artísticos, materiales, históricos, culturales y devocionales de la iglesia, acentuando las fiestas y celebraciones religiosas que se desarrollan en el poblado y en el templo como un valor cultural religioso relevante. Una vez analizada la importancia de dichos valores, revisa el uso actual y propone conservarlo, ya que el templo se mantiene en servicio, efectuando celebraciones litúrgicas y recibiendo a misioneros. A continuación, revisa la administración actual del bien y propone tres alternativas para su manejo: a) población local y organizaciones representativas, b) servicios públicos, y c) obispado de Arica y comunidad tradicional. Tras evaluar las alternativas, recomienda la tercera y, además, confecciona un organigrama de roles que cumplirá cada parte constituyente. 
Figura 3. Planta general del templo (primer nivel)

Fuente: SUBDERE, 2014, p. 64.
Figura 4. Estado interior de la iglesia antes de la intervención

Fuente: SUBDERE / Fundación Altiplano Monseñor Salas Váldez, 2011, p. 17.

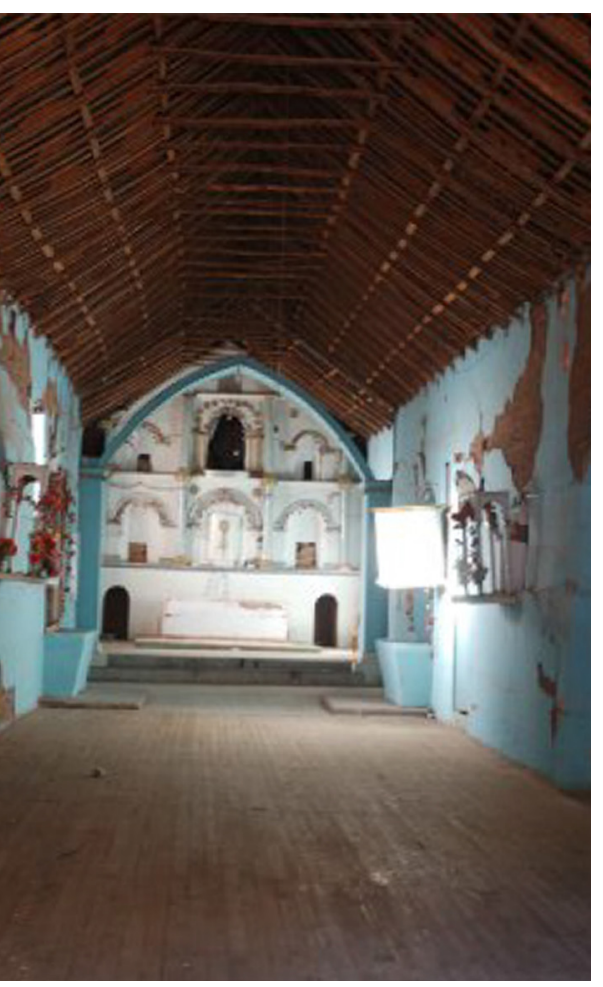

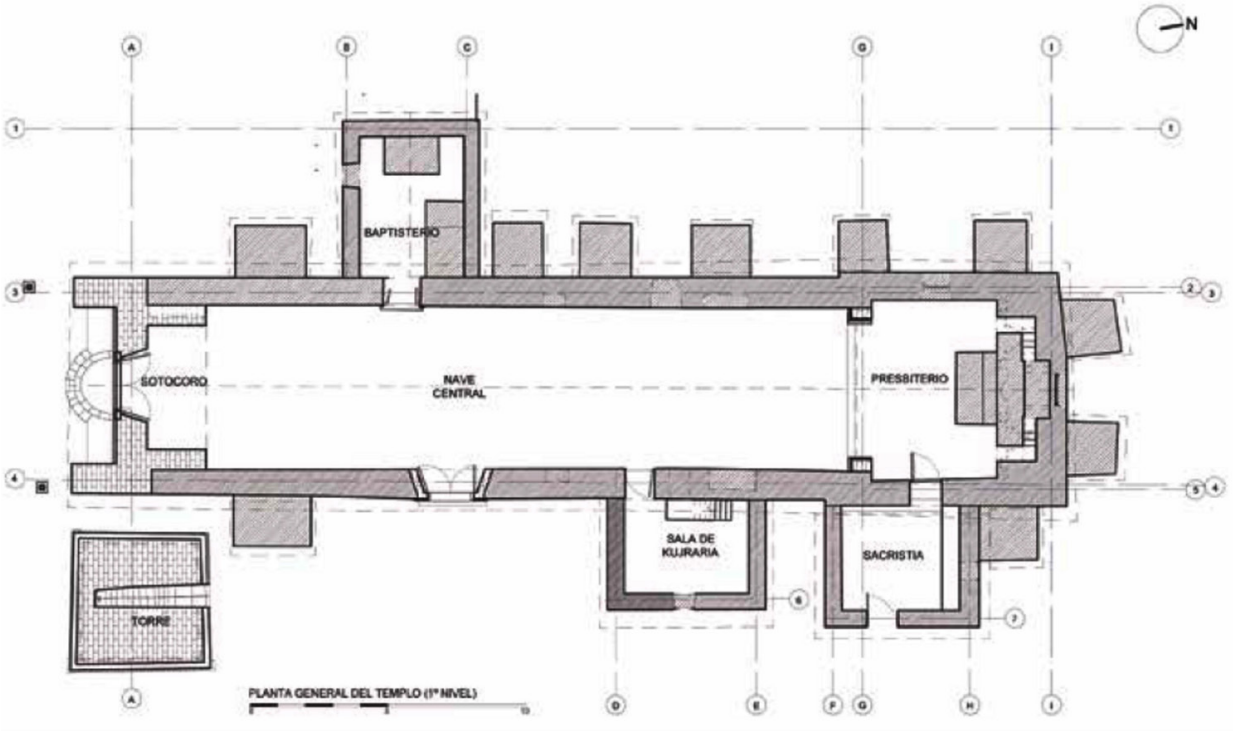

El modelo propuesto para la iglesia de Socoroma sugiere mantener y potenciar su sistema tradicional de conservación y administración, ya que ha demostrado ser exitoso durante siglos. Este sistema descansa en la responsabilidad legal del obispado de Arica, propietario del inmueble, que garantiza el culto y uso público del bien restaurado, y cuenta con el apoyo y compromiso permanente de la comunidad usuaria, que participa de manera coordinada por medio de los cargos tradicionales de fabriquero, mayordomo y alférez.

Como se señaló anteriormente, el plan de gestión se concreta a partir del Plan de Restauración del Conjunto Patrimonial de Iglesias Andinas de Arica y Parinacota, que busca poner en valor 30 templos, de los cuales la iglesia de Socoroma es uno. De acuerdo al modelo de gestión, el objetivo principal es consolidar las iglesias andinas de Arica y Parinacota como uno de los conjuntos patrimoniales más valiosos de América y potenciarlas como un bien de desarrollo sostenible para sus comunidades. Asimismo, se busca implementar un mapa de gestión que incorpore metas e indicadores, que, a su vez, permitan contar un medio de medición una vez ejecutado el modelo.

El programa de operación definirá las acciones concretas que permitirán la puesta en marcha y trabajo de la iglesia. En este punto destacan las actividades litúrgicas, las fiestas religiosas y las visitas turísticas. De igual manera, establece quiénes son responsables de dichas actividades, así como la organización y coordinación de estos actores.

Cabe enfatizar que este modelo de gestión desarrolla un esquema de manejo para la conservación, mediante el cual se considera al proyecto de restauración como parte de una intervención de manejo integral, que implica la suma de distintas disciplinas para el manejo de los bienes patrimoniales. Con respecto al mantenimiento, el modelo propone diversas tareas que cumplir para la correcta subsistencia del bien; también anexa recomendaciones en caso de situaciones adversas (ej. sismos). Dentro del contenido relacionado a la protección y seguridad de la iglesia, se señala que la comunidad estará a cargo de resguardar el bien, lo cual es una manera de comprometerla con el cuidado de su patrimonio. El modelo finaliza con una propuesta de gestión financiera donde se estima los costos anuales totales, los cuales se proyectan frente a los ingresos totales anuales estimados, e incluye un análisis de sensibilidad y riesgos. 

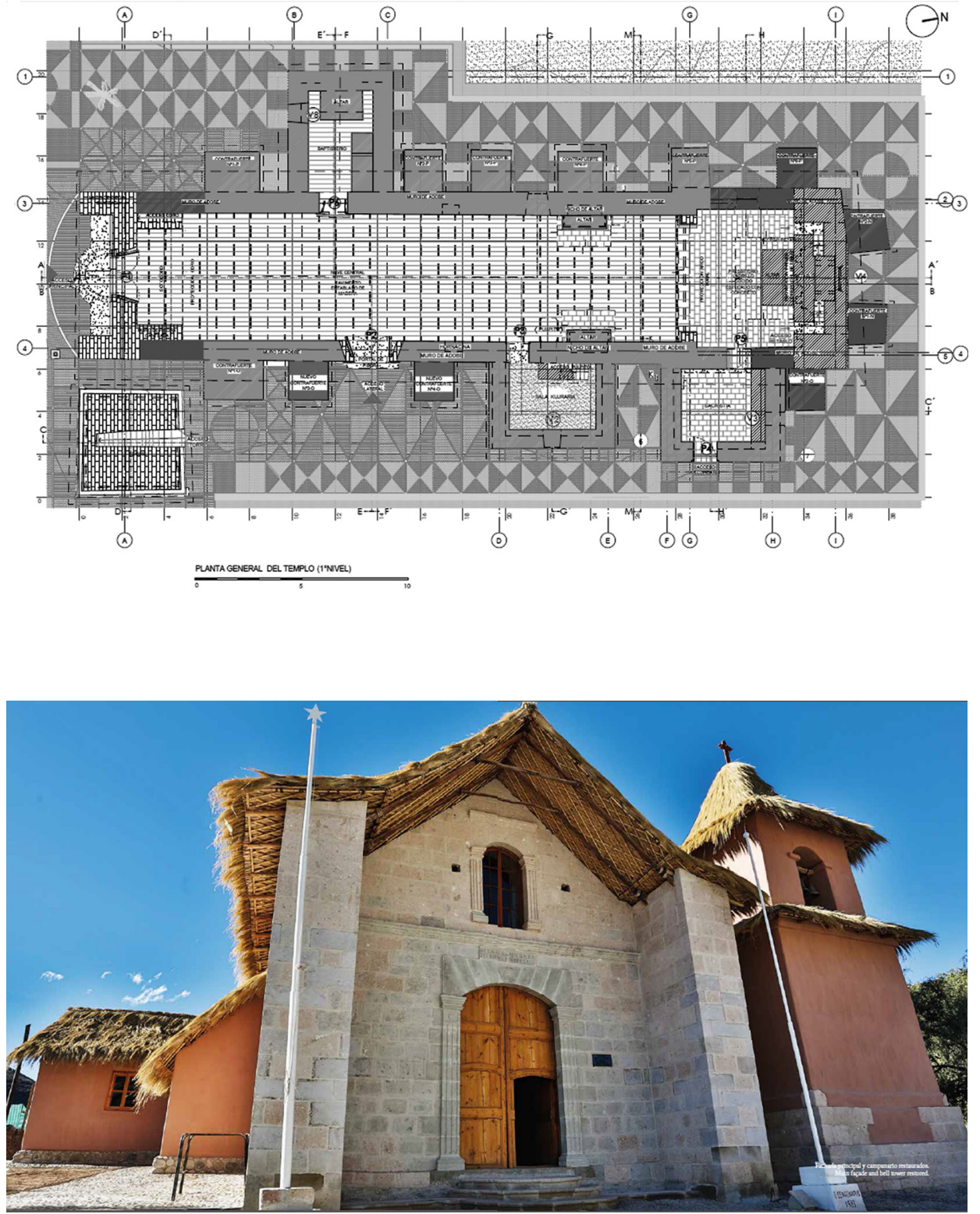

Figura 5. Planta de intervención general del templo (primer nivel)

Fuente: SUBDERE / Fundación Altiplano Monseñor Salas Váldez, 2011, p. 3.
Figura 6. Fachada de la iglesia de Socoroma, restaurada

Fuente: SUBDERE, 2014, p. 147-148.

Figura 7. Vista interior del templo restaurado

Fuente: Foto Bruno Boggioni, 2013.

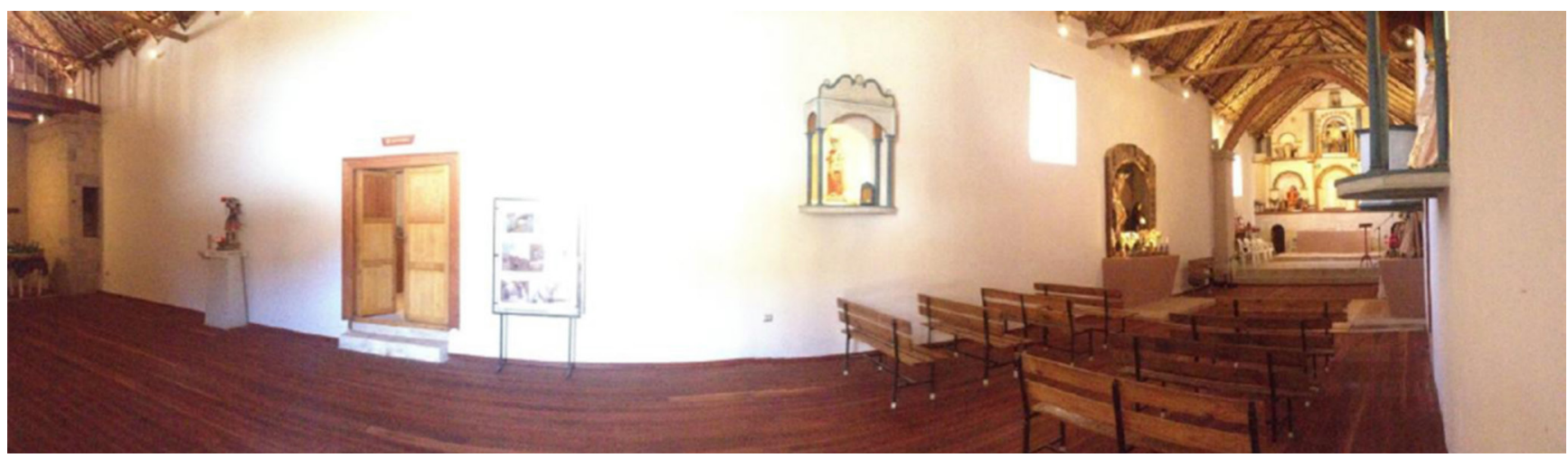


devenir Vol. 2, N4, JULIO-DICIEMBRE 2015, pp. 127-149 - EstudIOS I ISSN 2312-7570

UnIVERSIDAD NaCIONAL dE INGENIERÍA, LIMA

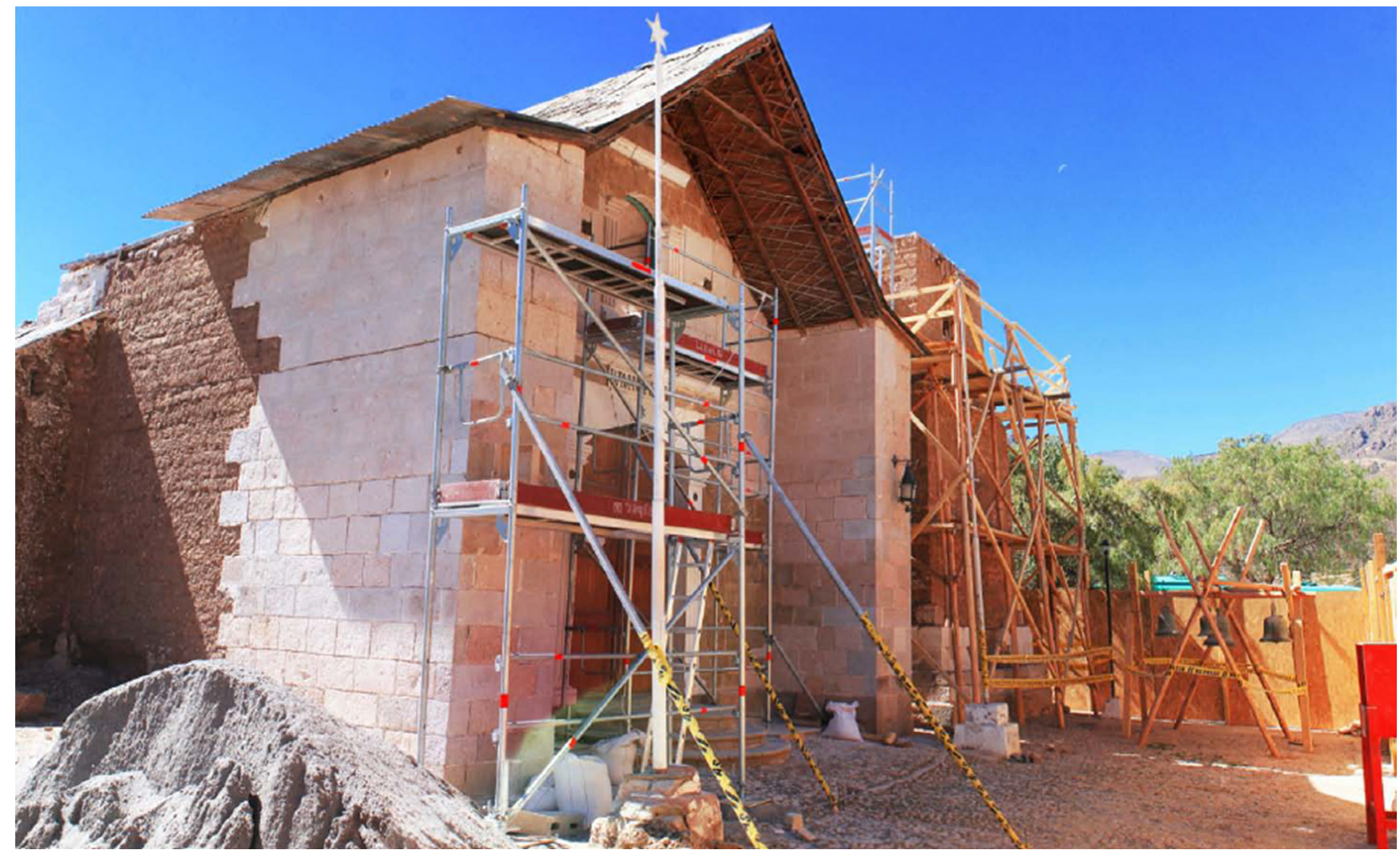

Figuras 8. Trabajos de restauración,

fachada de la iglesia de Socoroma

Fuente: Foto Bruno Boggioni, 2012.

Figuras 9. Trabajos de restauración,

interior de la iglesia de Socoroma

Fuente: Foto Bruno Boggioni, 2012.

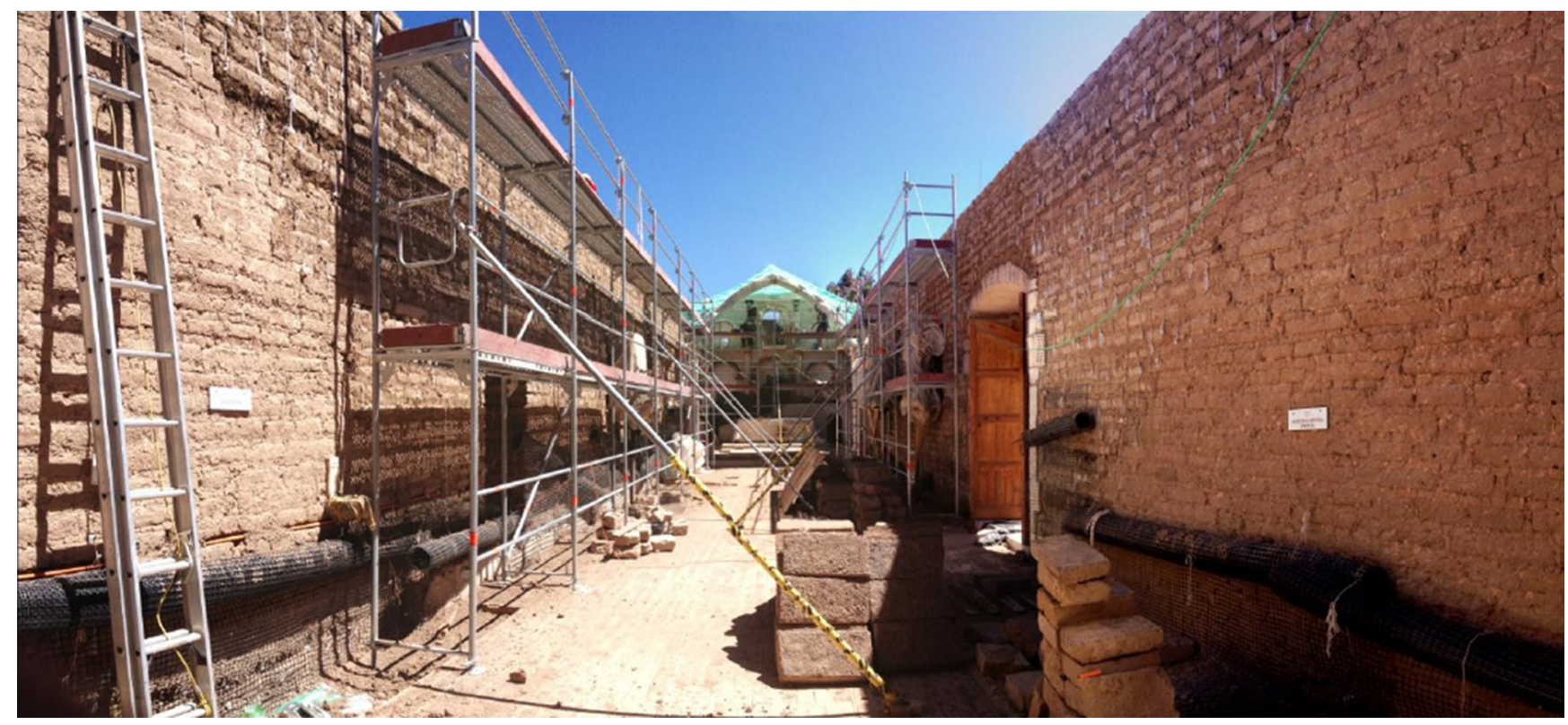


Los impactos previstos son la viabilidad socioeconómica, la posibilidad de sostener los costos derivados de las actividades de operación, mantenimiento y protección del templo mediante la contribución conjunta del Obispado de Arica, los habitantes de Socoroma y los descendientes del lugar comprometidos con el templo. Desde la viabilidad sociocultural, el modelo se enfoca en conservar y potenciar el valor patrimonial de la iglesia y de sus bienes culturales, protegiéndolo de los agentes de riesgo para bien de la comunidad usuaria que está a cargo de su conservación.

En la restauración de la iglesia se considera la figura de escuela taller, donde a los integrantes de la comunidad interesados en participar de la restauración se les ofrece una capacitación remunerada, durante el primer mes; posteriormente, aquellos que manifiesten mayor interés y capacidad son contratados. Dada la forma en que se ejecuta el proyecto de restauración del templo, incorporando e incentivando económicamente a la población, se demuestra el interés por ocupar mano de obra local y generar empleabilidad, lo cual es de vital importancia en una comunidad que muestra tendencia al despoblamiento. En el caso de la iglesia de Socoroma, hay una profunda identificación de la comunidad con su templo, lo que se hace evidente en las celebraciones religiosas que se festejan en la iglesia, así como en la reiterativa la solicitud, por parte de la comunidad, para la restauración de su patrimonio.

En conclusión, la restauración de la Iglesia San Francisco de Asís de Socoroma se enmarca en la conceptualización de la puesta en valor del patrimonio, donde esto último se entiende como sostenibilidad económica para el funcionamiento y mantención de los templos en el tiempo. Para ello la intervención de restauración se plantea como parte de un plan integral, donde colaboran distintas disciplinas en el manejo de los bienes patrimoniales. El proyecto presenta iniciativas no solo de restauración de los templos, sino también de investigación, recuperación de obras de artes y bienes muebles, y, por último, de sensibilización de la población (Figura 11).

\section{Modelo de Gestión Habilitación de la Biblioteca Pública Regional en el Edificio de Ex Correos de Antofagasta}

El caso se centra en la habilitación de un edificio patrimonial de inspiración neoclásica francesa, construido entre los años 1921 y 1930. Desde su construcción el edificio ha albergado principalmente servicios públicos. Un aspecto importante a destacar es su ubicación en la plaza principal de la ciudad, en la que, además, ocupa un espacio significativo (Figuras 12 y 13 ).

Al igual que el modelo presentado anteriormente, este se ordena a partir del levantamiento y diagnóstico, mas se distingue por el hecho que, al ser una construcción de gran superficie y con diversos accesos, ha sido utilizado paralelamente por diversas instituciones públicas: Correos de Chile, Juzgados, Corte de Apelaciones, Asociación Regional de Municipalidades, y Consejo de Artes y Cultura. Estos organismos se encargaban del pago de servicios y de administrar los espacios de forma separada; sin embargo, no se preocupaban de la conservación general del recinto.

En el desarrollo de los valores que se asignan a la edificación, se señala los valores culturales e históricos. Se reconocen los valores culturales a través de la identidad, manifiesta mediante el reconocimiento de la obra por parte de la comunidad, principalmente por sus características arquitectónicas y su dimensión. Por su parte, el valor histórico se presenta a través de su tipología. Construido para ser un edificio de servicios públicos, ha mantenido esa ocupación a lo largo del tiempo. De entre los servicios que ahí han operado, cabe destacar las oficinas del Telégrafo y la Delegación Fiscal de Salitreras, pues marcan una época económica y tecnológicamente importante para la región y el país. Adicionalmente a los valores mencionados, hoy la biblioteca forma parte del circuito turístico patrimonial de la ciudad, para el cual es importante proteger y resguardar las edificaciones que lo conforman (Figura 14).

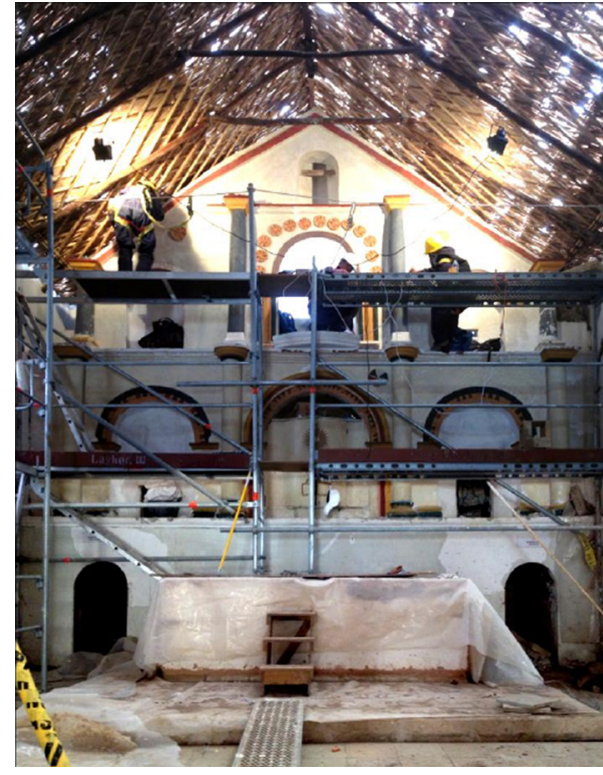

Figuras 10. Trabajos de restauración, iglesia de Socoroma

Fuente: Foto Bruno Boggioni, 2012.

Figura 11. Trabajos de restauración de bienes culturales muebles, iglesia de Socoroma

Fuente: Foto Bruno Boggioni, 2013.

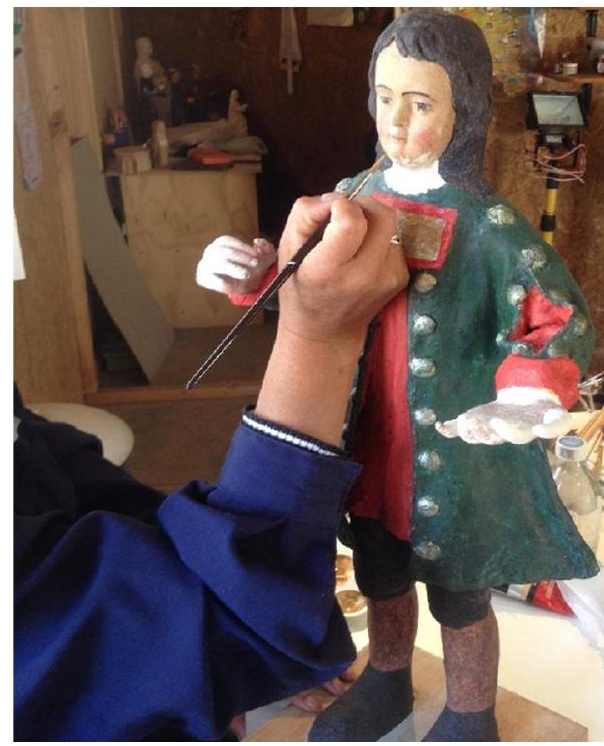


devenir Vol. 2, N4, JULIO-DICIEMBRE 2015, pp. 127-149 - EstudIOS I ISSN 2312-7570

UnIVERSIDAD NACIONAL DE INGENIERÍA, LIMA

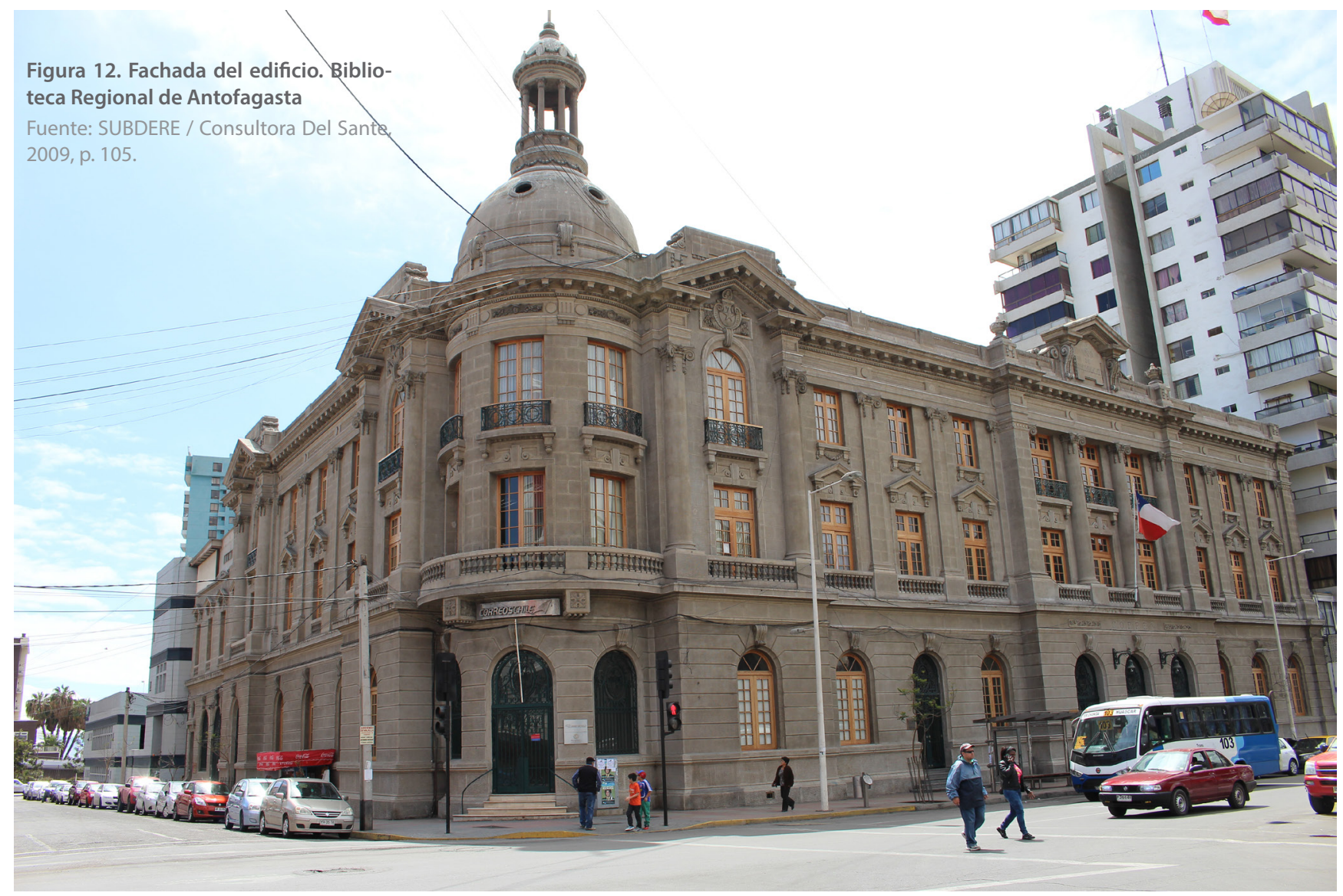

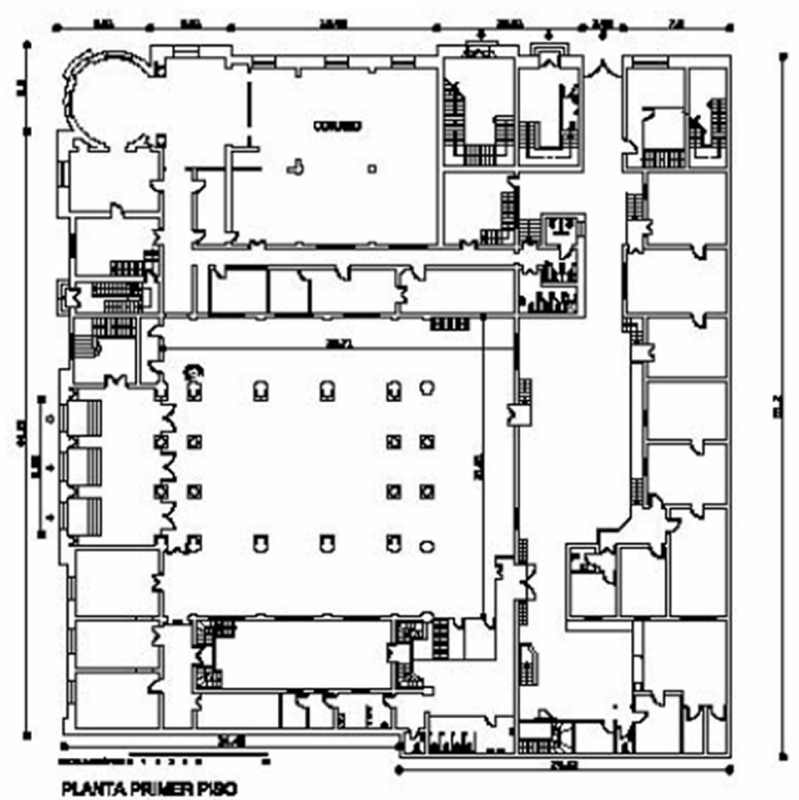

Figura 13. Plano original del edificio

Fuente: SUBDERE / Consultora Del Sante, 2009, p. 106.

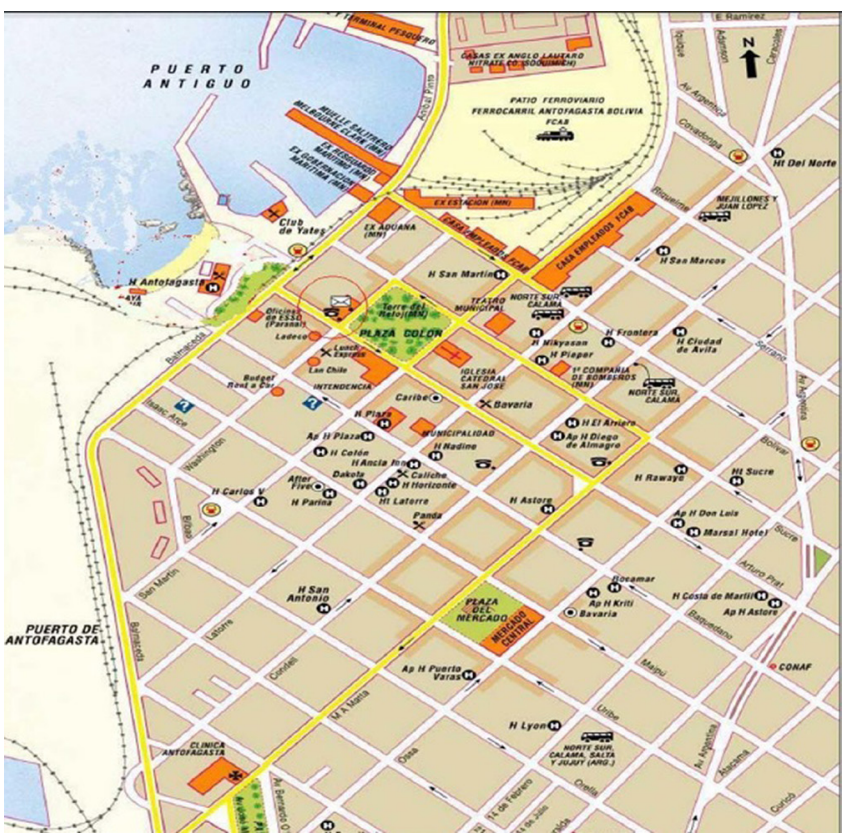

Figura 14. Plano del circuito turístico, Antofagasta Fuente: SUBDERE / Consultora Del Sante, 2009, p. 10. 

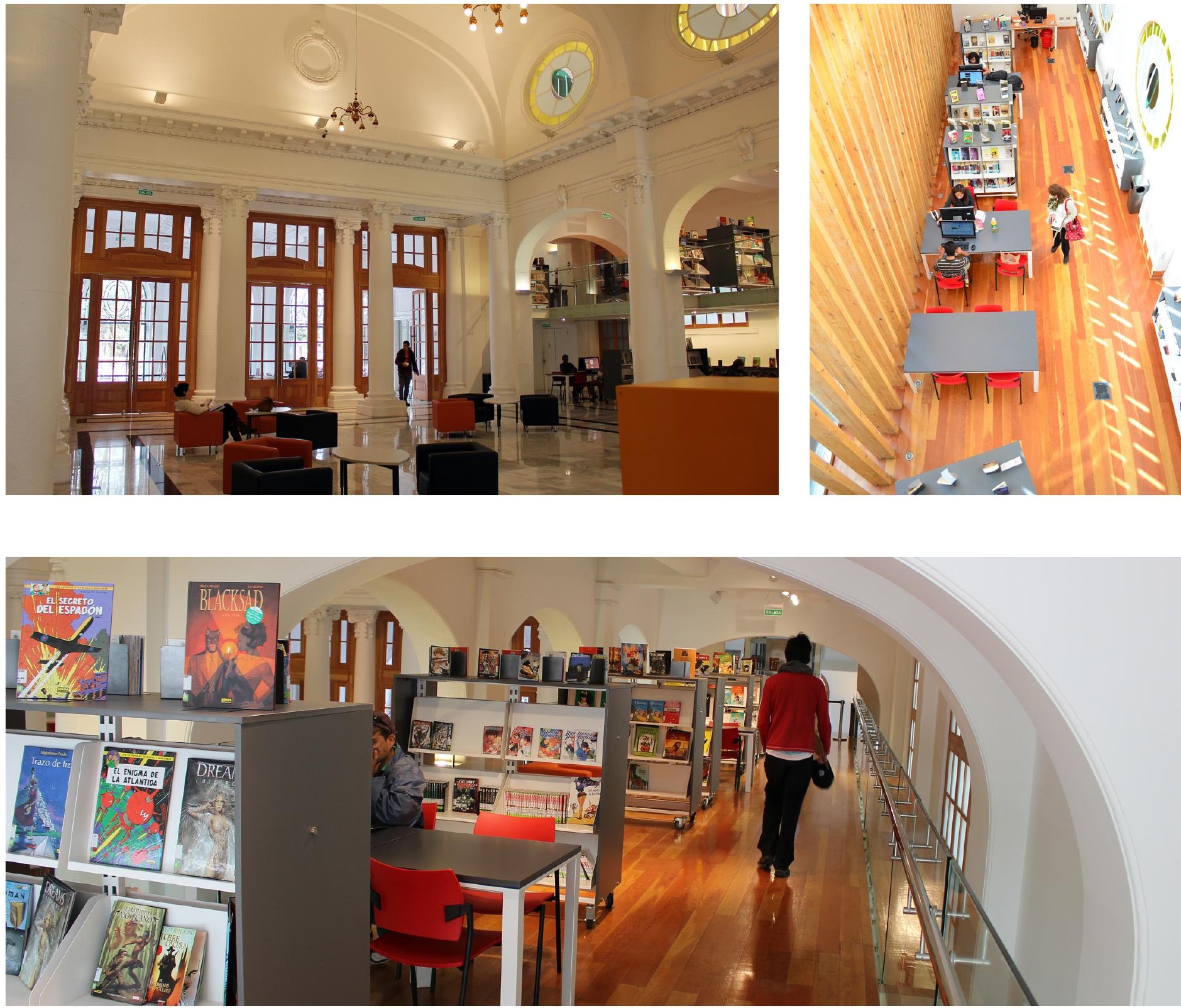

La propuesta de uso se plantea de acuerdo a sus características arquitectónicas, a su organización interior y a su ubicación. Tomando esto en cuenta, se recomiendan tres alternativas de uso: a) museo regional, b) biblioteca pública regional y c) sede central universitaria. La alternativa que destaca es la segunda, dado su alto valor patrimonial y, principalmente, a cuenta de su distribución interior, que se caracteriza por la gran flexibilidad y amplitud de sus espacios, lo cual permite la apropiación del recinto, y facilidades para el acceso y el recorrido de este (Figuras 15, 16 y 17).

Cabe destacar que otro de los factores que se consideró para la elección fue el hecho de que en la ciudad solo existían tres bibliotecas públicas para una población de 380,695 habitantes; por ello, la biblioteca tiene como finalidad cubrir dicha necesidad, servir como lugar de investigación y lectura, y finalmente convertirse en un centro de contacto con la cultura.
Figura 15. Hall de acceso Fuente: Foto DIBAM, 2016I

Figura 16. Zona de lectura Fuente: Foto DIBAM, 2016.

Figura 17. Zona de lectura y circulación

Fuente: Foto DIBAM, 2016. 

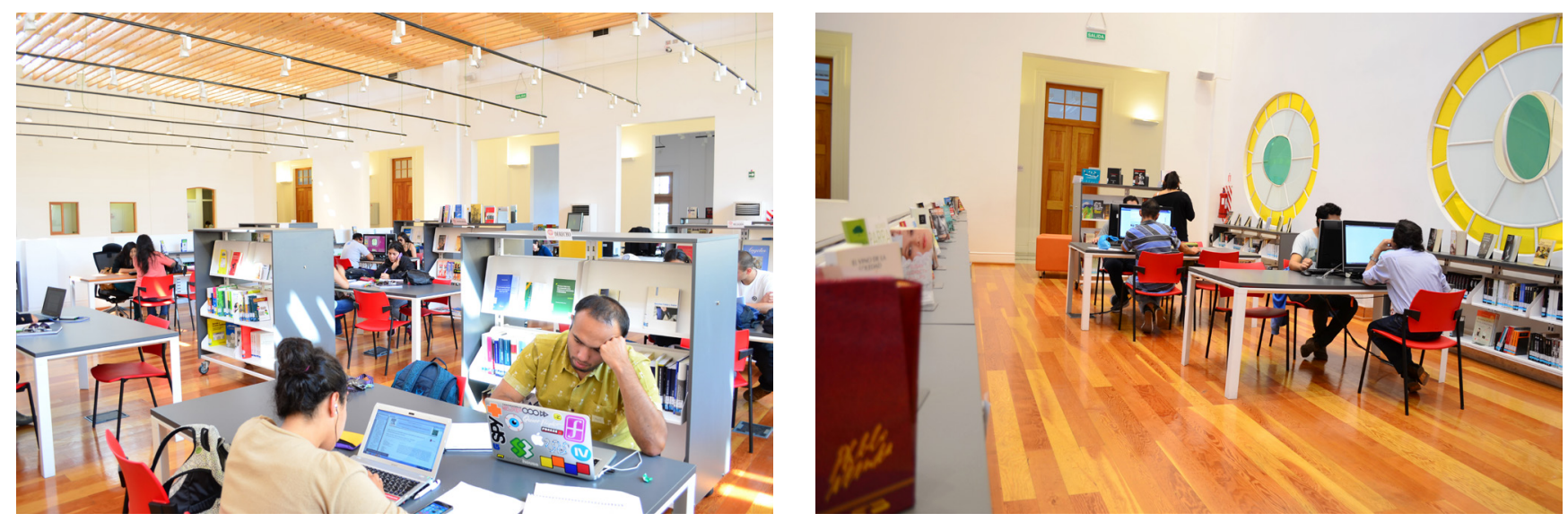

Figura 18. Colección general Fuente: Foto DIBAM, 2016.

Figura 19. Sala de Literatura Fuente: Foto DIBAM, 2016.
Posteriormente, en el análisis de la unidad de gestión, se define quienes administrarán el edificio y se proponen dos organismos: a) la Dirección de Bibliotecas, Archivos y Museos (DIBAM), y b) el Consejo de la Cultura y las Artes. Tras evaluar las alternativas, se recomienda a la DIBAM. A razón de que en este caso en particular se busca que la iniciativa beneficie a la comunidad, brindando un espacio abierto enfocado a la cultura y a la educación, se opta por implementar un órgano administrador que sea capaz de generar y procurar sus propios recursos a invertir. La DIBAM, como unidad gestora, es una organización con extensa experiencia en administrar bienes culturales o patrimoniales, y aumentar su valor. De la organización y coordinación estará a cargo la Unidad de Coordinación Regional de Bibliotecas de Antofagasta, dependiente de la DIBAM central. Esta unidad cuenta con un organigrama de los roles que cumplirá cada parte constituyente y con una definición de cargos tipificados desde el nivel central.

El plan de gestión se delimita a partir de la habilitación y nuevo uso que se propone de 'biblioteca híbrida', un recinto que albergue diversas colecciones de publicaciones impresas y de diversos formatos tecnológicos; asimismo, que cuente con variados servicios, tales como cines, salas de exposición, salas de reunión, auditorios, cafeterías, etc., pensados para atender a múltiples usuarios, de diferentes edades y estratos sociales. Los principales objetivos del modelo de gestión se enfocan en lo social y lo cultural, reconociendo la sustentabilidad desde cuatro puntos fundamentales: a) liderazgo de su directiva, b) sustentabilidad en su financiamiento, c) capacitación permanente para sus operadores y d) evaluación de sus logros en forma periódica. En este sentido la DIBAM, como unidad gestora, será la encargada de administrar los recursos entregados por el Ministerio de Hacienda, que financiará los gastos de operación de la biblioteca año a año. Estos recursos cubrirán honorarios, manutención, seguridad y gastos básicos de servicios.

Una de las acciones a implementar que destacan son las 'transferencias culturales', actividades que permitan la posibilidad de facilitar los espacios de extensión de forma gratuita a la sociedad, por ejemplo, para organizar charlas, foros, exposiciones, obras de teatro, etc. De esta manera se busca incorporar e interactuar con la comunidad, y generar cultura abierta y accesible para la población (Figuras 18 y 19).

A continuación se elabora el programa de operación, el cual se centra en definir las actividades concretas a llevar a cabo. En este caso se divide en dos áreas principales: la biblioteca, es decir, la codificación, registro y préstamos de libros entre otros servicios; y la unidad de extensión, o sea, la ocupación de los espacios complementarios con la realización de charlas, foros, exposiciones, etc. 

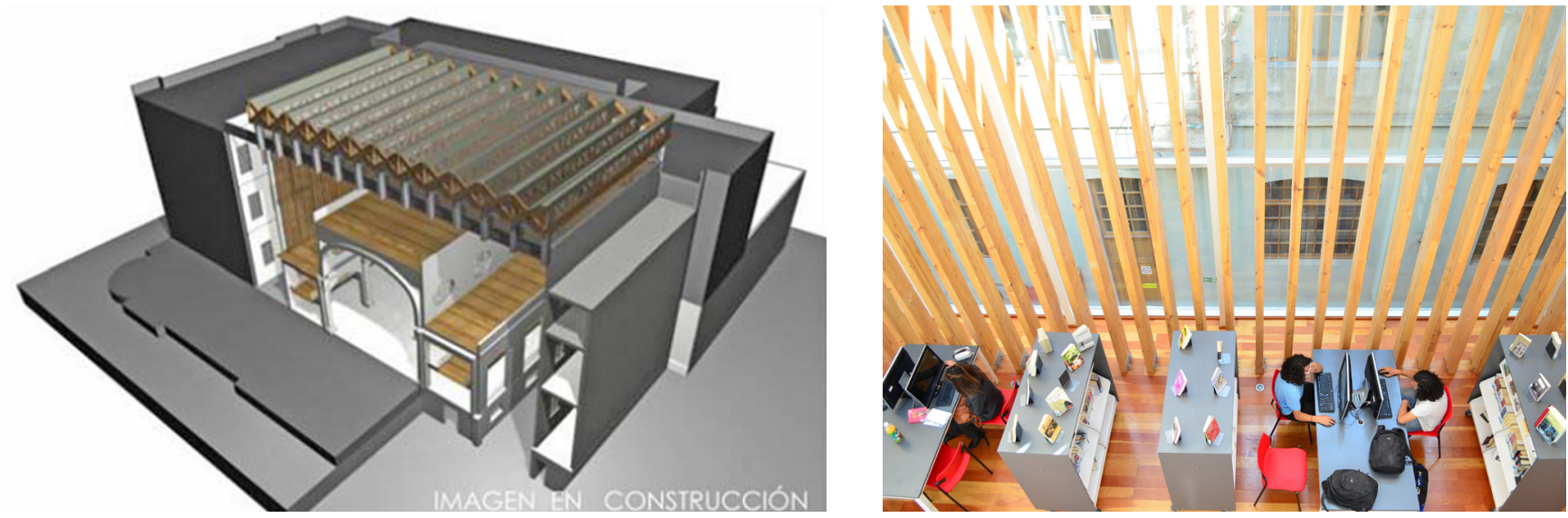

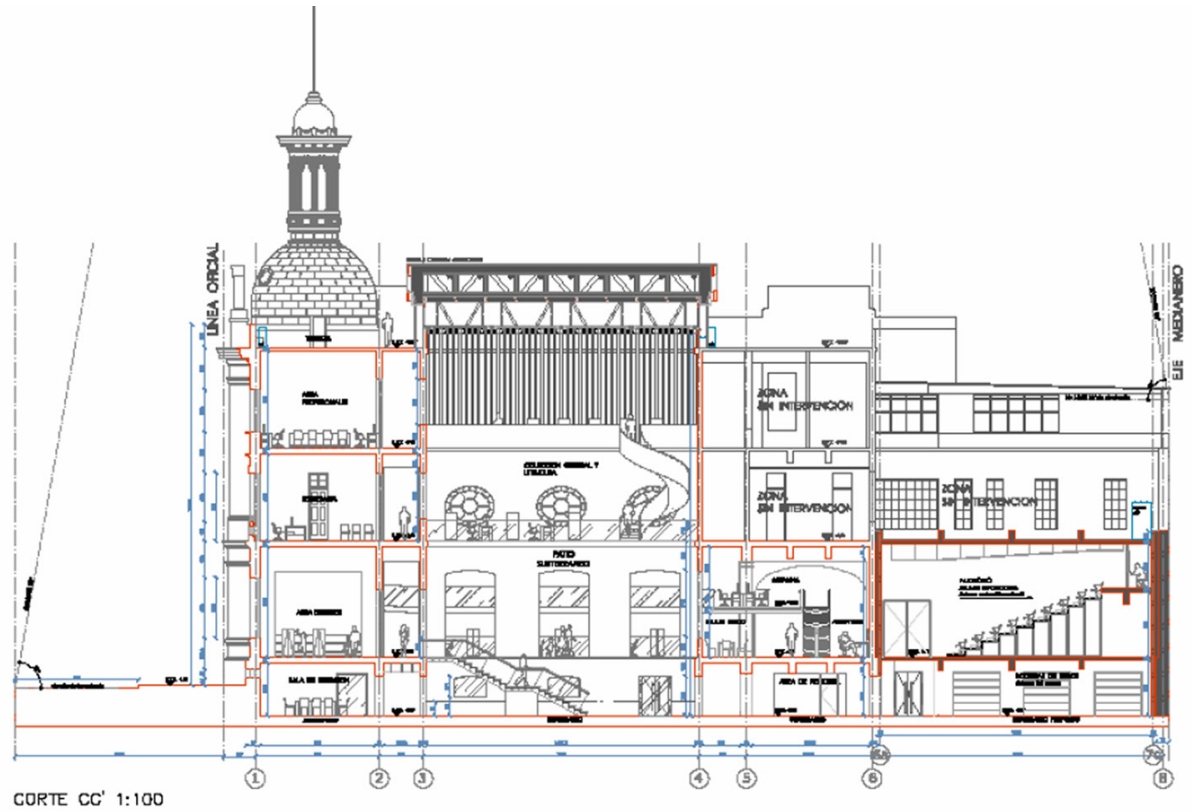

Con respecto al proyecto de intervención, se opta por una habilitación restaurativa del inmueble, que permita adaptar todo el edificio para su utilización por la biblioteca y sus oficinas. Se regularizan las instalaciones eléctricas y sanitarias, para ofrecer iluminación, climatización y seguridad. Además, se recuperan las características espaciales originales del diseño y se mejora la luz para la lectura. La intervención se propone en la parte del área declarada Monumento Histórico, y mantiene a los usuarios existentes en las áreas que no se intervienen (Figuras 20, 21 y 22).

Al igual que el modelo anterior, se agrega una propuesta de manutención, que en este caso se divide en dos áreas: la manutención para uso diario como biblioteca y la manutención del bien patrimonial. Se definen las labores concretas y se anexa la periodicidad necesaria de los trabajos para mantener el patrimonio arquitectónico en óptimo estado de conservación. Dada la envergadura y características de uso del edificio, el plan de protección y seguridad recomienda un sistema mixto de seguridad, conformado por vigilantes y un sistema electrónico de vigilancia.
Figura 20. Imagen virtual, propuesta de intervención

Fuente: SUBDERE / Consultora Del Sante, 2009 , p. 38.

Figura 21. Corte, Proyecto Habilitación Biblioteca Regional de Antofagasta

Fuente: SUBDERE / Consultora Del Sante, 2009 , p. 39.

Figura 22. Adaptación del edificio para mejorar la luminosidad Fuente: Foto DIBAM, 2016. 
devenir Vol. 2, N²4, JULIO-DICIEMBRE 2015, PP. 127-149 - EstudIOS I ISSN 2312-7570

UNIVERSIDAD NACIONAL DE INGENIERÍA, LIMA

Figura 23. Planta general y elevación principal, Escuela Antigua de Cerro Castillo antes de la intervención Fuente: Archivo DIBAN, 2016.

Figura 24. Fachada, Escuela Antigua de Cerro Castillo antes de la intervención

Fuente: Ilustre Municipalidad de Rio Ibáñez, 2016.

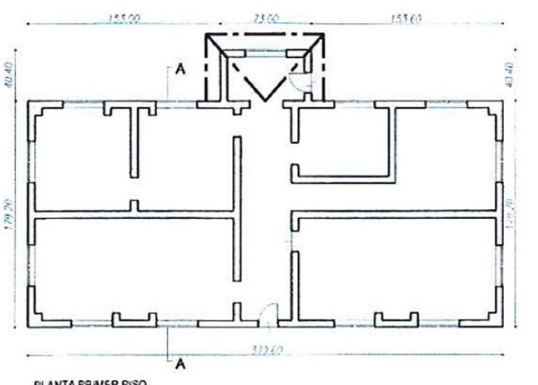

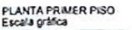

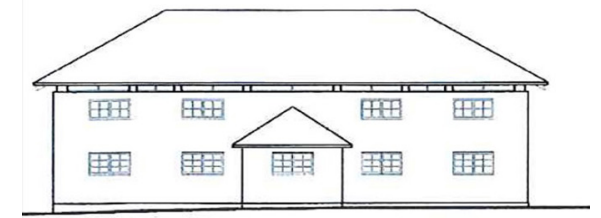

furiosionst
Finalmente, la gestión financiera desarrolla los costos operacionales y los ingresos proyectados, donde, aunque los ingresos propios que generará el bien por su propia operatividad y servicios son de poca relevancia con respecto a los gastos, estos serán considerados para su análisis. Cabe recordar que en este caso el funcionamiento de la biblioteca (manutención, operación, etc.) será financiado a través de un presupuesto sectorial de la DIBAM.

Entre los principales impactos socioculturales previstos están los siguiente: transformar la biblioteca en un lugar de encuentro, poniendo a disposición de la comunidad las herramientas, el ambiente, el personal, la tecnología de punta y la información; proveer una gestión cultural que incentive el descubrir y desarrollar cultura; y preservar un bien patrimonial que posee singulares características arquitectónicas y constructivas a través de la implementación de un uso armónico a sus valores culturales e históricos.

En conclusión, el modelo de gestión Habilitación Biblioteca Pública Regional en el Edificio de Ex Correos de Antofagasta basa su sostenibilidad en los beneficios socioculturales del proyecto, lo que se ve reflejado en la capacidad de la institución para incorporar a la comunidad como usuario permanente de la biblioteca y ser un centro de difusión cultural para la población. La sustentabilidad económica será medida a través de la capacidad de la unidad administradora para gestionar adecuadamente los recursos con los que cuenta, a fin de conseguir la mayor retribución y beneficio sociocultural.

\section{Modelo de Gestión Museo de Sitio Escuela Antigua de Cerro Castillo}

El tercer modelo de gestión a analizar se proyecta partir de un antiguo edificio construido en el año 1955 para ser una escuela. Esta iniciativa busca vincular la construcción con los sitios arqueológicos emplazados en su entorno y con el patrimonio natural circundante. En este caso, más allá de los antecedentes patrimoniales del inmueble, resalta su emplazamiento en un lomaje abierto dentro de un valle amplio con el cordón montañoso del Cerro Castillo de fondo (Figura 23, 24 y 25).

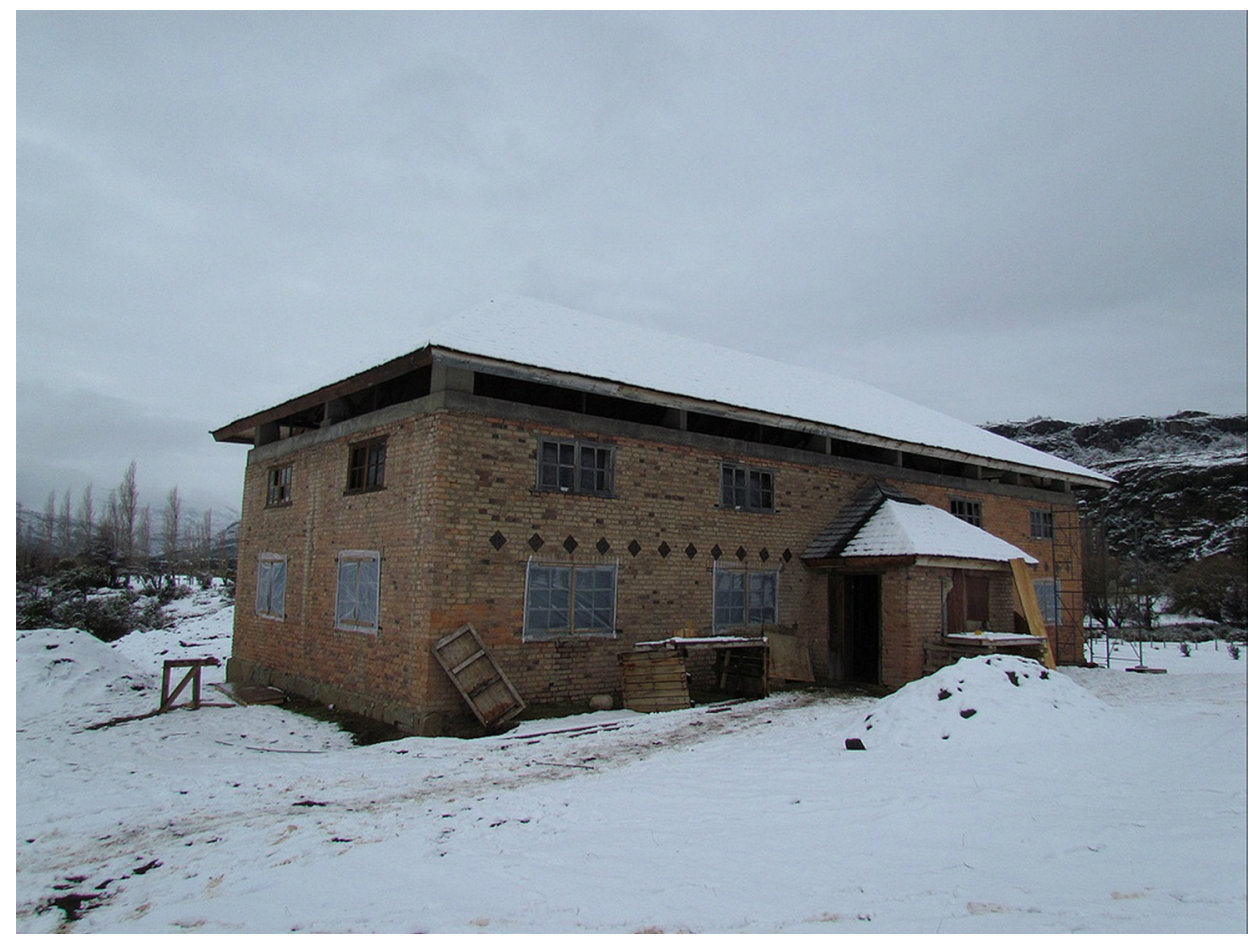



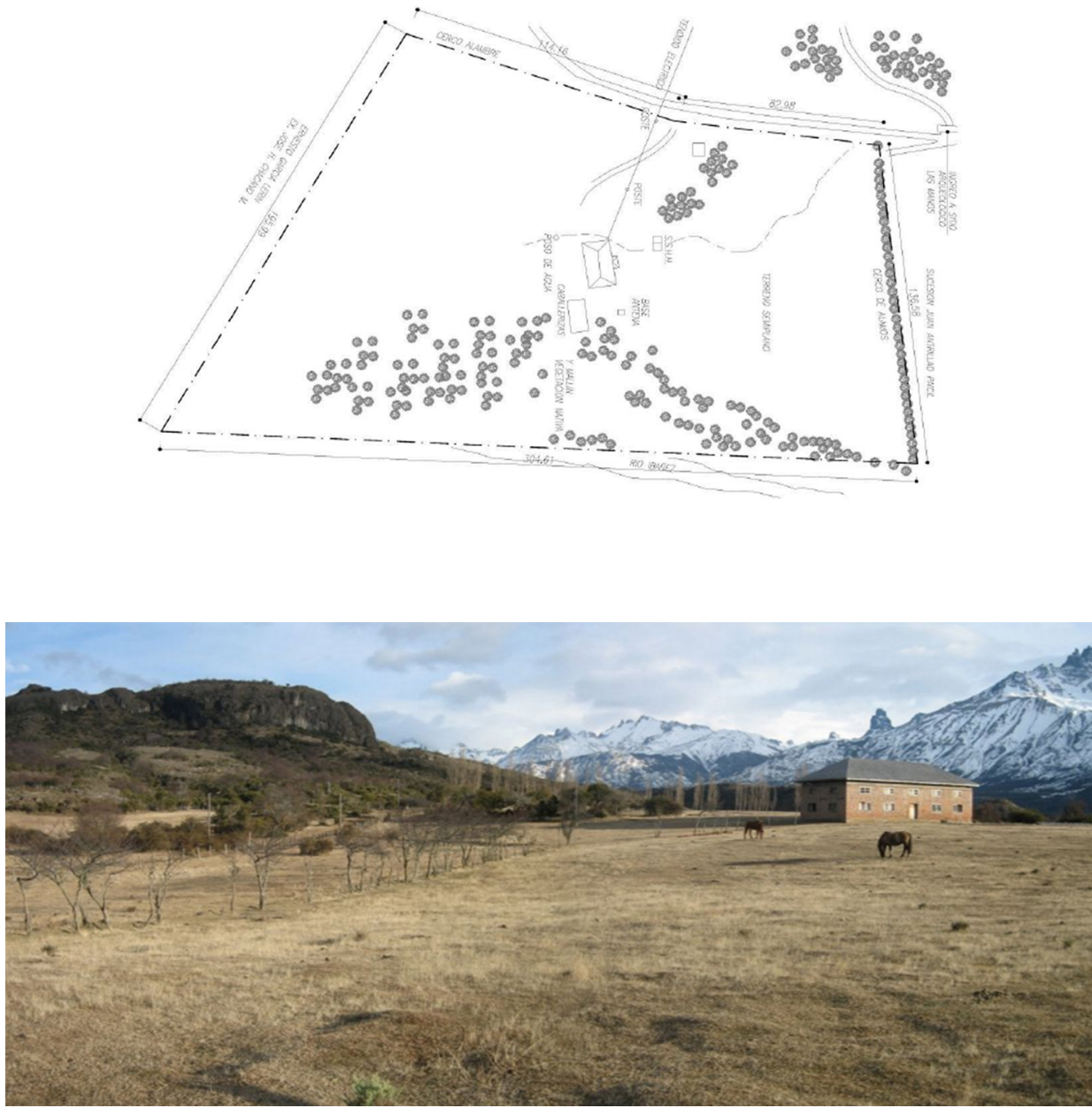

Acerca del diagnóstico y levantamiento cabe recalcar que el edificio fue utilizado como escuela esporádicamente hasta 1975 y que, al momento de la iniciativa, el monumento se encontraba en desuso y en evidente estado de abandono, a pesar de que en el año 1997 fue remodelado estructuralmente para habilitarlo como salón museográfico de la cultura Tehuelche, presente en la zona con más de 60 sitios arqueológicos.

Sobre los valores que presenta la construcción se señalan el social-histórico, el arquitectónico y el paisajístico. Los primeros se desarrollan a partir de la condición de aislamiento que presenta la región de Aysén y principalmente el valle del río lbañez. Este sector fue poblado paulatinamente por la comunidad mapuche, la cual asumió las acciones necesarias para la ocupación y colonización de un espacio geográfico extremadamente difícil para el asentamiento, entre ellas la construcción e implementación de la escuela, orientada a la educación de sus propios hijos y a revertir la baja de alfabetismo originada por la inexistencia de un establecimiento de esta categoría. Sus valores arquitectónicos se observan en su forma de volumen sólido y compacto, con vanos simétricos donde predomina el ladrillo como material. Finalmente, el paisajístico destaca entre sus valores, ya que su emplazamiento es único, un entorno natural conformado por el volcán Hudson, el río Ibáñez y el cerro Castillo.
Figura 25. Plano de emplazamiento, Escuela Antigua de Cerro Castillo Fuente: SUBDERE / Gobierno Regional de Aysén, 2010, p. 9.

Figura 26. Museo de Sitio, Escuela Antigua de Cerro Castillo y su entorno

Fuente: Ilustre Municipalidad de Rio Ibáñez, 2016. 
devenir Vol. 2, N4, JULIO-DICIEMBRE 2015, pp. 127-149 - EstudIOS I ISSN 2312-7570

UNIVERSIDAD NACIONAL DE INGENIERÍ, LIMA

Figura 27. Trabajos de restauración, Museo de Sitio Escuela Antigua de Cerro Castillo

Fuente: Ilustre Municipalidad de Rio Ibáñez, 2016.

Figura 28. Fachada, Escuela Antigua de Cerro Castillo

Fuente: Ministerio del Interior y Seguridad Pública / Subsecretaría de Desarrollo Regional y Administrativo, 2014, p. 143.
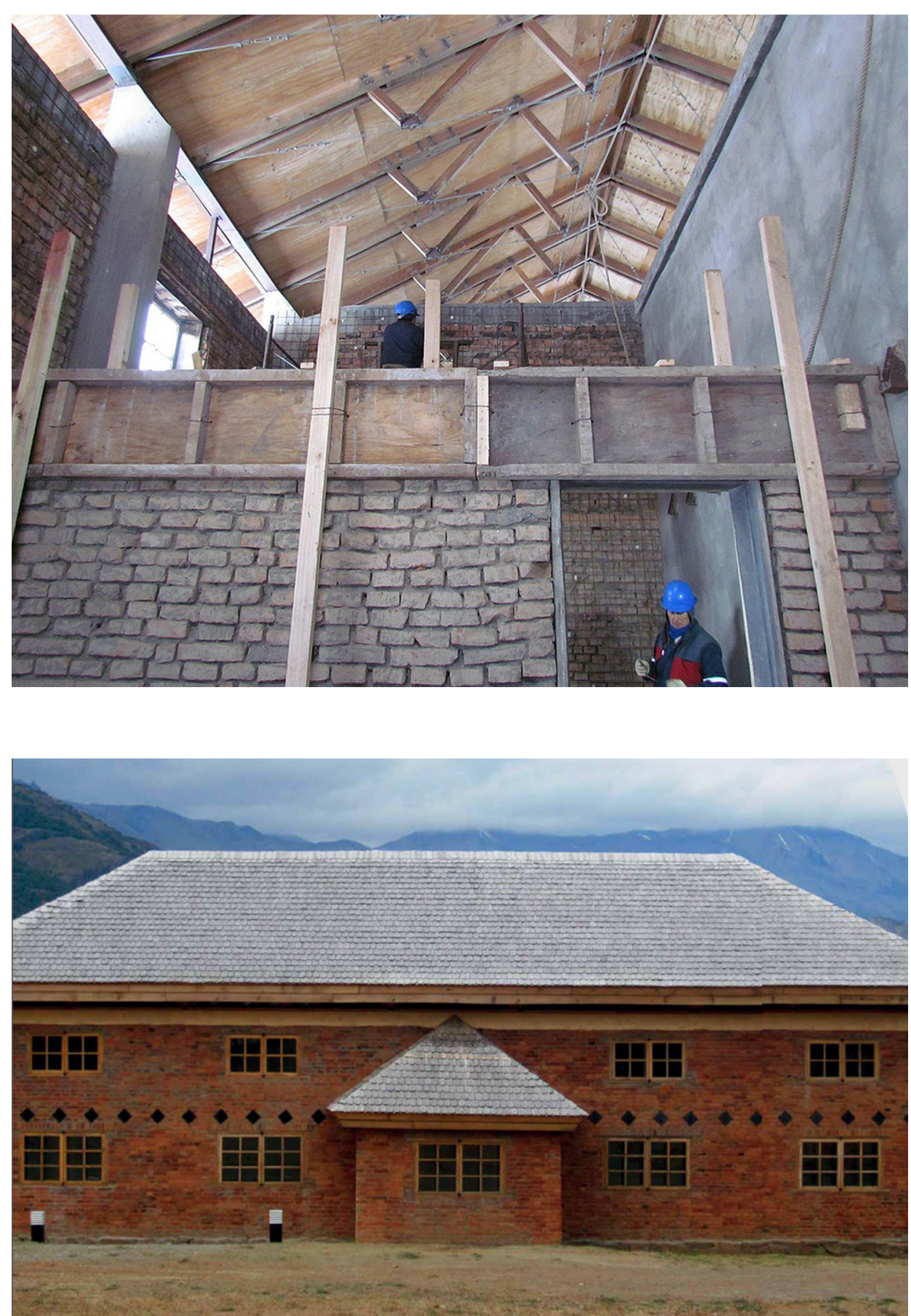

En este caso la propuesta de uso se elabora a partir de un proceso comunitario y participativo, del cual se distinguen dos alternativas: a) casa del Área de Conservación de la Cultura y el Ambiente (ACCA) de la Patagonia, y b) museo de sitio. Desde el año 1997 diversas instituciones públicas han mantenido el interés en el resguardo del edificio; finalmente, el año 2007 se obtuvo financiamiento para la iniciativa Restauración Escuela Antigua para uso de museo de sitio, Cerro Castillo, siendo el uso de museo de sitio la alternativa mejor evaluada para la conservación y protección del inmueble, y de su entorno. 
Como unidad de gestión se exponen cuatro alternativas: a) la llustre Municipalidad de Río Ibáñez, b) una corporación municipal, c) el Centro de Investigación de Ecosistemas de la Patagonia (CIEP), d) una corporación regional de desarrollo cultural. De las cuatro alternativas señaladas, dos son unidades que se crearían para fines administrativos, lo cual representa una demora para la puesta en marcha de la iniciativa, por lo que se opta por la llustre Municipalidad de Río Ibáñez. Esta institución, a través de la firma de convenios contará con el apoyo de tres actores interesados en las actividades de difusión e investigación. El museo de sitio quedará bajo el mando de la Oficina de Fomento Productivo, dependiente del Departamento Social y Desarrollo Comunitario de la Municipalidad. Esta oficina, a través de un coordinador del museo de sitio, estará a cargo de la organización y administración del recinto.

El plan de gestión radica no solo en la implementación del museo de sitio, sino en el reconocimiento de un entorno aislado que presenta un alto valor paisajístico. Además, se proyectan senderos que permiten observar el medio natural y encontrar los restos arqueológicos diseminados en medio de la naturaleza. De los objetivos sociales, económicos y culturales presentados se señala el "Fortalecer, relevar y difundir la identidad comunitaria mediante la puesta en valor de la Antigua Escuela de Cerro Castillo, cuyo uso como Museo de sitio permitirá mostrar parte de su historia y abrir espacios para el desarrollo de actividades costumbristas y/o tradicionales" (SUBDERE / Gobierno Regional de Aysen, 2010, p. 47). De esta forma se busca incentivar la participación de la comunidad y destacar el esfuerzo realizado para poblar la región.

Al igual que en los modelos anteriores, el programa de operación asignará los procedimientos necesarios para el correcto funcionamiento del museo. En este caso se centrará en definir actividades relacionadas con los sitios arqueológicos y el paisaje que se desarrollarán al interior del museo, y en su entorno.

El proyecto de intervención Restauración Monumento Nacional Escuela Antigua Cerro Castillo en Río Ibáñez considera un plan maestro para ocupar la totalidad del terreno donde se inserta. Además de la restauración del edificio, proyecta la construcción de una nueva edificación destinada a la actividad museográfica, investigativa y de extensión, así como la propuesta de diseño para las vías peatonales de su entorno circundante (Figuras 27 y 28 ).

El modelo aborda el programa de manutención desde tres aristas: el mantenimiento preventivo básico, que comprende las labores para el correcto funcionamiento del museo; el mantenimiento preventivo secundario, que incorpora las tareas de limpieza y cuidado en profundidad; y el mantenimiento correctivo, que implica las acciones que buscan prevenir el descaste por uso del edificio, y permiten la recuperación, restauración o renovación de elementos que constituyen la infraestructura o planta física del mismo.

La localidad presenta un muy bajo nivel de robos y vandalismos, por lo que no se considera la necesidad de contar con guardianía; sin embargo, al ser infraestructura municipal están obligados a la contratación de un seguro.

Por último, se elabora la gestión financiera, elaborando los flujos correspondientes a los costos de operación y los ingresos a generar. En este modelo los ingresos necesarios se obtendrán de cuatro fuentes de financiamiento: a) generación de ingresos propios, b) aportes directos de la Municipalidad, c) donaciones y d) aporte de los socios estratégicos. Al ser cuatro los financistas, se recomienda una planificación detallada, a fin de que los recursos sean apropiadamente destinados.

En cuanto a los impactos socioculturales, se busca posicionar al Museo Escuela Antigua de Cerro Castillo como un referente turístico-cultural de la región de Aysén, mediante su valorización como Monumento Nacional y su apertura a la comunidad. Por 
otro lado, el impacto socioeconómico proyectado es potenciar la economía local mediante la generación de pequeños espacios de emprendimiento.

En conclusión, el modelo de gestión del Museo de Sitio Escuela Antigua de Cerro Castillo se enfoca en desarrollar la sostenibilidad desde el ámbito sociocultural y socioeconómico. Presenta una propuesta de participación activa de la comunidad y, a su vez, incorpora actividades mediante las cuales emprendedores y/o microempresarios puedan vincularse con el museo y potenciar el desarrollo local. Pero, sobre todo, la sustentabilidad se muestra a partir de la consideración del entorno, paisajes y sitios arqueológicos en el modelo de gestión. Se presenta así un plan de gestión no solo para la edificación, sino también para lo circundante; considera el paisaje como recurso que genera beneficios sociales, culturales y económicos, y que, por lo tanto, al igual que el edificio, se debe proteger y resguardar.

\section{Conclusiones Finales}

En los casos analizados se observan importantes valores adyacentes a los bienes patrimoniales; en cada caso estos valores se diferencian de acuerdo al patrimonio a intervenir, siendo únicos e irrepetibles. Al identificar estos valores también se reconoce el ámbito, propósito y quehacer del patrimonio arquitectónico para la comunidad actual y futura.

Además, cada modelo presenta alternativas de unidades de gestión diferenciadas, el obispado de Arica para la Iglesia San Francisco de Asís de Socoroma, la DIBAM para la Habilitación de la Biblioteca Pública Regional en el Edificio de Ex Correos de Antofagasta y la llustre Municipalidad de Río Ibáñez para el Museo de Sitio Escuela Antigua de Cerro Castillo. En cada caso son estudiadas y analizadas varias unidades gestoras, y se recomienda al ente administrativo con mayor competencia, ya sea por cercanía a la comunidad, por su experiencia en determinado tipo de iniciativas, o por su capacidad de administrar y contar con recursos propios, entre otras cualidades.

El uso otorgado a los tres edificios analizados presenta un fuerte carácter público; en las recomendaciones de los modelos de gestión se aprecia que uno de ellos mantiene su uso original, mientras que dos de ellos se habilitan para un nuevo uso. Es importante observar que este carácter público no se basa precisamente en una ocupación turística, sino que se enfoca en las poblaciones residentes, lo que permite una mayor cercanía con la población y vincula al patrimonio a un gran beneficio social. Asimismo, los beneficios socioeconómicos de dos de los modelos (iglesia y museo) incorporan actividades productivas, ya sean capacitaciones o espacios de emprendimiento, mientras que la biblioteca se enfoca en los beneficios socioculturales, pues cuenta con financiamiento externo. Se puede observar que la sustentabilidad, en cada caso, difiere en su campo de acción; es decir, los benéficos esperados responden a diversos ámbitos (sociales, culturales y económicos), por lo que es mediante el manejo integral que es posible realizar intervenciones de mayor eficiencia y eficacia.

En resumen, considerando que generalmente los recursos a invertir en los proyectos de conservación y puesta en valor son públicos, es necesario asegurar la manutención y costos operativos de los bienes patrimoniales, invirtiendo en modelos de gestión particulares e individuales para cada edificio, que modelen la realidad particular del inmueble, y muestren a la población que los habitará y a su entorno inmediato sus valores patrimoniales, ya sea del medio natural o urbano. Un modelo de gestión recomendará, si es necesario, la adecuación del uso del bien, a fin de satisfacer las necesidades actuales, para que su ocupación sea permanente en el tiempo proyectado. Además, los modelos de gestión exponen una gestión económica efectiva y realista, que implica su conservación y preservación.

Lo expuesto resalta la importancia de generar un modelo de gestión anterior o paralelo al proyecto de restauración del edificio a intervenir, para de esta manera asegurar a 
largo plazo el compromiso de la unidad gestora y la comunidad, y, a su vez, la sostenibilidad del bien e integración de la población que lo habitará.

Los proyectos analizados en este artículo presentan dicho modelo de gestión, lo que permitirá a las entidades públicas realizar un seguimiento en el tiempo de las iniciativas implementadas en cada caso, además de visualizar el impacto de las mismas a largo plazo, a través de los beneficios sociales, culturales o económicos que dan cuenta de los logros o consecuencias positivas que se pueden obtener al realizar una intervención integral en torno al patrimonio, más allá de los objetivos inmediatos asociados al modelo.

\section{Referencias}

"Gestión". (2013). Diccionario de la Real Academia de la Lengua Española. Recuperado de www. rae.es

"Modelo". (2013). Diccionario de la Real Academia de la Lengua Española. Recuperado de www. rae.es

Amat, J. (1992). El control de gestión: Una perspectiva de dirección. Barcelona, España: Gestión 2000 S.A.

Banco Interamericano de Desarrollo. (2008). Programa Puesta en Valor del Patrimonio. Recuperado de www.idbdocs.iadb.org/wsdocs/getdocument.aspx?docnum=1343105

Consejo de Europa. (1975). Declaración de Amsterdam. Recuperado de www.icomoscr.org/doc/ teoria/VARIOS.1975.declaracion.amsterdam.patrimonio.arquitectonico.europeo.pdf

Ilustre Municipalidad de Río Ibáñez. (2016). Museo Escuela Cerro Castillo. Recuperado de www. museoescuela-cerrocastillo.cl/museo-escuela

Mason, R. (2002). Assessing values in conservation planning: Methodological issues and choices. California: The J. Paul Getty Trust.

ONU. (3 al 14 de junio de 1992). Declaración de Río sobre el medio ambiente y el desarrollo. Recuperado de www.un.org/spanish/esa/sustdev/agenda21/riodeclaration.htm

Sanabria, M. (2007). De los conceptos de administración, gobierno, gerencia, gestión y management: Algunos elementos de corte epistemológico y aportes para una mayor comprensión. Recuperado de www.redalyc.org

SUBDERE - Consultora del Sante. (2009). Modelo de gestión habilitación biblioteca pública regional en el edificio ex-Correo Antofagasta. Antofagasta, Chile: Autor.

SUBDERE - Fundación Altiplano Monseñor Salas Váldes. (2011). Modelo de gestión para proyecto de restauración de la iglesia de Socoroma. Arica, Chile: Autor.

SUBDERE - Gobierno Regional de Aysen. (2010). Modelo de gestión museo de sitio Escuela Antigua de Cerro Castillo. Aysen, Chile: Autor.

SUBDERE - Ministerio del Interior y Seguridad Pública. (2014). Puesta en valor del patrimonio. Recuperado de www.subdere.gov.cil/sites/default/files/documentos/interior_patrimonio_1. pdf

SUBDERE. (2010). Guía metodológica para la elaboración de modelos de gestión del patrimonio cultural inmueble. Santiago, Chile: Autor.

SUBDERE. (2011). Guía operativa del programa Puesta en valor del patrimonio. Santiago, Chile: Autor.

UNESCO. (1962). Carta internacional sobre la conservación y la restauración de monumentos y sitios. II Congreso Internacional de Arquitectos y Técnicos de Monumentos. Venecia, Italia: Autor. 